This is a so-called personal version (author's manuscript as accepted for publishing after the review process but prior to final layout and copyediting) of the article:

Sarala, Riikka and Vaara, Eero. 2003. Cultural differences, convergence, and crossvergence as explanations of knowledge transfer in international acquisitions. Journal of International Business Studies, 2010, 4: 1365-1390.

Researchers are kindly asked to use the official publication in references.

\title{
Cultural differences, convergence, and crossvergence as explanations of knowledge transfer in international acquisitions
}

\author{
Riikka Sarala \\ Department of Business Administration, Bryan \\ School of Business and Economics, University of \\ North Carolina at Greensboro, Greensboro, USA
}

And

\section{Eero Vaara}

Department of Management and Organization

Hanken School of Economics

PO Box 479, 00101 Helsinki, Finland

EM Lyon Business School, Strategy \&

Organization, Lyon, France 


\section{Abstract (summary)}

In spite of the proliferation of research on cultural differences in international mergers and acquisitions, we lack systematic analyses of the impact of cultural factors on knowledge transfer. In this paper, we argue that both national and organizational cultural differences and cultural integration in the form of cultural convergence and crossvergence affect knowledge transfer in acquisitions. We develop specific hypotheses concerning the nature of these effects, and test our hypotheses with data on international acquisitions carried out by Finnish corporations. The analyses performed show that national cultural differences provide great potential for knowledge transfer in international acquisitions. Furthermore, organizational cultural convergence and crossvergence have a significant positive impact on knowledge transfer. In particular, convergence and crossvergence moderate the impact of national cultural differences on knowledge transfer.

\section{INTRODUCTION}

It is widely understood that knowledge is a key resource that contributes to corporate renewal and competitive advantage. In particular, international acquisitions are often motivated by the desire to gain access to new knowledge and transfer existing knowledge between the acquiring and the acquired firms (Björkman, Stahl, \& Vaara, 2007; Bresman, Birkinshaw, \& Nobel, 1999; Empson, 2001; Ranft \& Lord, 2002). Previous acquisition studies have suggested several reasons for the success or failure of knowledge transfer. These include factors such as type of knowledge (Ranft \& Lord, 2002), integration strategy (Birkinshaw, 1999; Buono, 1997), employee reactions (Empson, 2001), communication (Bresman et al., 1999; Buono, 1997), and use of expatriates (Hébert, Very, \& Beamish, 2005). However, our understanding of how cultural factors influence knowledge transfer in acquisitions remains limited (Björkman et al., 2007). This has unfortunately prevented researchers from fully comprehending one of the key mechanisms through which cultural factors may affect postacquisition outcomes.

Hence our purpose is to clarify the role of cultural factors as explanations of post-acquisition knowledge transfer. Rather than pursue a simplistic approach that focuses on national cultural differences alone, we examine how both national and organizational cultural differences affect knowledge transfer. Such an approach has been called for in recent critical analyses of the cultural literature on mergers and acquisitions (M\&As) (Angwin \& Vaara, 2005; Stahl \& 
Voigt, 2005, 2008; Teerikangas \& Very, 2006). We argue that it is only by examining both layers of the double acculturation processes (Barkema, Bell, \& Pennings, 1996; Nahavandi \& Malekzadeh, 1988) that we can see how the positive or negative effects are played out. In particular, we suggest that even though national cultural differences may increase social conflict, they may also serve as sources of knowledge transfer because of the potentially useful diversity of practices, beliefs, and values residing in and around merging organizations. Similar views have been recently advanced by other scholars as well (Bhagat, Kedia, Harveston, \& Triandis, 2002; Björkman et al., 2007). Most notably, Björkman et al. (2007) have outlined a theoretical model of capability transfer that provides theoretical grounds for the potential of complementarity linked with national cultural differences. Our intention is to draw from this analysis, but also to take a step further to elaborate specific hypotheses and test them empirically.

Furthermore, we argue that it is paramount to focus on the process of cultural integration that is, on the development of organizational culture with compatible beliefs, values, and practices (Haspeslagh \& Jemison, 1991; Nahavandi \& Malekzadeh, 1988; Shrivastava, 1986). Previous studies have suggested that cultural integration is crucial for enabling knowledge transfer in acquisitions (Björkman et al., 2007; Bresman et al., 1999; Buono, 1997). However, this research has not distinguished between different mechanisms through which cultural integration takes place and how they affect knowledge transfer in acquisitions. Drawing on seminal research in cross-cultural management (Ralston, 2008; Ralston, Holt, Terpstra, \& Kai-Cheng, 1997), we identify two mechanisms through which cultural integration can take place - organizational cultural convergence and organizational cultural crossvergence - and explore their influence on knowledge transfer in international acquisitions.

Consequently, the research question in this study is formulated as follows. How do cultural differences (national and organizational) and cultural integration (convergence and crossvergence) affect knowledge transfer in international acquisitions? In order to answer this research question, we develop specific hypotheses concerning the nature of these effects, and test our hypotheses with data from international acquisitions carried out by Finnish corporations.

The paper is structured as follows. We next provide an overview of research on knowledge transfer in international acquisitions, after which we turn to what is already known about cultural explanations of post-acquisition integration. This is followed by the development of 
our hypotheses. These are then tested in the next sections. In the final section, we discuss our results and present suggestions for future research as well as managerial implications.

\section{KNOWLEDGE TRANSFER IN INTERNATIONAL ACQUISITIONS}

An important part of the competitive advantage of multinational enterprises (MNEs) is their ability to make use of knowledge residing in geographically dispersed units (Doz, Santos, \& Williamson, 2001; Grant, 1996; Gupta \& Govindarajan, 2000). This implies a broad view on knowledge that includes all kind of explicit or implicit knowledge embedded in different parts of MNEs. More specifically, following Zander and Kogut (1995), we define knowledge as the accumulated practical skill or expertise that allows one to do something smoothly and efficiently.

This knowledge-based view of the firm means that unique stocks of knowledge in different subsidiaries and specific ways of integrating and organizing knowledge by the firm can support its competitive advantage (Ghoshal, 1987; Grant, 1996; Nonaka, 1994). According to both the knowledge management (Nonaka, 1994) and resource-based views (Barney, 1991), knowledge that is difficult to imitate is particularly valuable. Such knowledge tends to be socially complex, embedded, and tacit (Barney, 1991; Nonaka, 1994). This implies that the processes of knowledge transfer within the MNE are complex, but crucial for sustaining competitive advantage (Bhagat et al., 2002; Björkman, Barner-Rasmussen, \& Li, 2004).

Through knowledge transfer, the unit is affected by the experience of another unit. Thus knowledge transfer is not mere replication, but usually involves recontextualization of the knowledge in the new context (Foss \& Pedersen, 2002). This means reapplying existing knowledge in a way that solves specific problems in a context different from that in which the knowledge originated, thereby producing benefits across different organizational functions (Zander, 1991). In other words, the actual value of knowledge transfer lies in the benefits of knowledge transfer to the recipient when the knowledge is reapplied and redeployed across different organizational functions of the receiving firm (Capron, Dussauge, \& Mitchell, 1998). Accordingly, we understand knowledge transfer as a successful process that results in benefits for the receiving unit (Bresman et al., 1999).

A number of studies have examined knowledge transfer in the acquisition context. Researchers have suggested that knowledge transfer is an important motive for acquisitions. 
Hitt, Hoskisson, and Ireland (1990) argued that gaining knowledge through an acquisition may enable the firm to expand its product lines without the risk involved in internal innovation. Teece, Pisano, and Shuen (1997) pointed to the role of acquisitions in decreasing transaction costs related to protecting knowledge, and Karim and Mitchell (2000) described acquisitions as vehicles to access and transfer tacit knowledge. Other scholars have examined the effects of knowledge transfer on the post-acquisition performance. For example, the empirical studies of Capron (1999) and Capron and Pistre (2002) showed that knowledge transfer was connected to abnormal returns in acquisitions. In addition, the multiple-case study of Ranft and Lord (2002) highlighted the importance of knowledge transfer for value creation in acquisitions in general.

Still other scholars have focused on post-merger integration (Birkinshaw, 1999; Bresman et al., 1999; Empson, 2001; Haspeslagh \& Jemison, 1991; Ranft \& Lord, 2002). In particular, Haspeslagh and Jemison (1991) connected knowledge transfer to value creation, which is defined as the improvement of a firm's competitive position and performance. According to this view, acquisitions are not one-off deals that focus on value capture. Acquisitions are instead seen as an important means of corporate renewal, which takes place through knowledge transfer between the partners during post-acquisition integration, and leads to competitive advantage (Haspeslagh \& Jemison, 1991; Larsson \& Finkelstein, 1999). Thus, within the process perspective on acquisitions, the focus is shifted from the specific financial end results to processes that facilitate knowledge transfer and consequently enhance the competitive advantage of the consolidated firm (Haspeslagh \& Jemison, 1991; Larsson \& Finkelstein, 1999).

These processes, however, also involve the "human side". For example, Buono (1997) emphasized the role of technology champions across functional areas, motivation efforts, and integration teams. Bresman et al. (1999) showed that communication, visits, and meetings facilitated knowledge transfer. Similarly, Birkinshaw (1999) concluded that an integration approach that fostered the emergence of a common culture before integrating the more technical parts of the acquiring and the acquired firms contributed to knowledge transfer. Furthermore, Empson (2001) showed how knowledge transfer depends on the perceptions of employees about each other and about the value of each firm's knowledge base.

It is noteworthy that these studies have not made an explicit linkage between cultural factors and knowledge transfer. The exception is the recent analysis of Björkman et al. (2007), which 
provides insights into the key mechanisms and processes. In brief, they argue that cultural differences affect capability transfer (which they use as a synonym for knowledge transfer) through their impact on capability complementarity, social integration, and absorptive capacity. The key point for our purposes is that the effect via capability complementarity is positive, whereas the impact through social integration is negative. What we wish to do is to outline specific hypotheses as to how exactly national and organizational cultural differences and cultural integration may affect knowledge transfer. This, however, requires a review of the existing studies on the impact of cultural factors in M\&As.

\section{CULTURAL EXPLANATIONS OF POST-ACQUISITION INTEGRATION}

In this paper, we adopt a "configurational" perspective according to which MNEs are cultural systems where beliefs, values, and practices form specific configurations in particular parts of the corporation. We argue that one can distinguish more fundamental cultural differences at the national level and then more apparent, surface-level differences at the organizational level. This conceptualization of culture coheres with Hofstede's (1980) ideas about underlying worldviews that are manifested in a "collective programming of the mind" as well as with the multilevel concept of culture adopted by the GLOBE research program (House, Hanges, Javidan, Dorfman, \& Gupta, 2004).

M\&A research has been dominated by financial analyses that focus on explaining the financial performance of acquisitions (King, Dalton, Daily, \& Covin, 2004). However, to understand the reasons for disappointments and failures in post-acquisition integration, M\&A scholars with a strategic and organizational orientation have increasingly drawn from analyses of organizational culture (Peters \& Waterman, 1982; Pettigrew, 1979) and national cultural differences (Hofstede, 1980). In fact, organizational cultural differences have been frequently used as indications and explanations of post-merger problems (Cartwright \& Cooper, 1993; Chatterjee, Lubatkin, Schweiger, \& Weber, 1992; Datta, 1991; Weber, Shenkar, \& Raveh, 1996). In international settings, researchers have concentrated on national cultural differences and their implications (Björkman et al., 2007; Larsson \& Finkelstein, 1999; Morosini, Shane, \& Singh, 1998; Olie, 1994; Slangen, 2006; Very, Calori, \& Lubatkin, 1993; Very, Lubatkin, Calori, \& Veiga, 1997; Weber et al., 1996). Most studies in this field have endorsed the argument that national cultural differences explain post-acquisition failure, although some studies have recently argued that cultural differences can also have a positive 
impact on post-acquisition performance (Chakrabarti, Gupta-Mukherjee, \& Jayaraman, 2009; Hébert et al., 2005; Larsson \& Finkelstein, 1999; Morosini et al., 1998; Slangen, 2006).

Such analyses have, however, been criticized. The use of simplistic "national cultural distance" measures has been seen as inadequate (Harzing, 2003; Kirkman, Lowe, \& Gibson, 2006; McSweeney, 2002; Shenkar, 2001). Moreover, it has been argued that many analyses have not given sufficient attention to other factors at play, or to the context-specific features (Stahl \& Voigt, 2005; Teerikangas \& Very, 2006). While these criticisms should be taken seriously, they do not mean that one should abandon the study of cultural differences altogether. Rather, the implication is that we need more elaborate cultural analyses of the various processes and mechanisms involved.

It is therefore important to recognize the importance of cultural integration processes. Drawing on anthropological models (Berry, 1983), several studies have examined the acculturation process following a merger or an acquisition (Elsass \& Veiga, 1994; Larsson \& Lubatkin, 2001; Nahavandi \& Malekzadeh, 1988). Scholars have, for example, examined how attractive the other organization is considered, and the kind of integration approach taken by the acquirer (Nahavandi \& Malekzadeh, 1988). Interestingly, Veiga, Lubatkin, Calori, and Very (2000) examined changes in cultural compatibility and found that the best performances were in cases where pre-merger cultural incompatibility turned into cultural compatibility after the merger. Larsson and Lubatkin (2001), in turn, found that successful acculturation is possible even in conditions of significant cultural differences if the acquirer invests in formal and informal social control.

But how do these cultural factors affect knowledge transfer? The recent analysis of Björkman et al. (2007) provides insights into the key mechanisms and processes, but their theoretical model does not make a distinction between national and organizational cultural differences, nor does it focus on the processes of cultural integration. Hence we now proceed to develop specific hypotheses concerning the impact of national and organizational cultural differences and cultural integration on knowledge transfer in international acquisitions. 


\section{THE IMPACT OF CULTURAL DIFFERENCES AND CULTURAL INTEGRATION ON KNOWLEDGE TRANSFER IN INTERNATIONAL ACQUISITIONS}

In order to clarify the explanatory value of cultural factors in connection with knowledge transfer in international acquisitions, we put forth a new kind of framework where we distinguish variables related both to cultural differences (national cultural differences and organizational cultural differences) and to cultural integration (cultural convergence and cultural crossvergence), and explore their influence on knowledge transfer. In this paper we define knowledge transfer as the benefits of the knowledge flows between the acquiring and the acquired firms (Björkman et al., 2007; Bresman et al., 1999). This conceptualization allows one to go beyond a teleological view that focuses only on intentional imposed oneway transfer of knowledge, and instead includes all kinds of knowledge transfer benefits that may result from post-merger integration. Following the example of others (Björkman et al., 2007; Bresman et al., 1999), we understand knowledge transfer as successful knowledge transfer, which means that it results in benefits for the receiving units.

\section{Cultural Differences}

\section{National cultural differences}

National culture can be defined as the collective programming of the mind acquired by growing up in a particular country (Hofstede, 1991). National culture is reflected in basic values, such as feelings of right and wrong, good and evil, beautiful and ugly, rational and irrational (Olie, 1994). In order to understand how national cultures differ, several authors have identified systematic national cultural differences along specific dimensions (Hofstede, 1980, 1991; Inglehart, Basáñez, Díez-Medrano, Halman, \& Luijkz, 2004; Schwartz, 2004; Trompenaars \& Hampden-Turner, 1998).

Previous studies in this area suggest that national cultural differences can create fundamental problems for integration - and thus also for knowledge transfer. A central reason is that national cultural differences are linked with national identity-building that often impedes cooperation (Olie, 1994; Vaara, 2003; Weber et al., 1996). This is because people tend to associate similarity with attractiveness and trustworthiness, whereas differences easily lead to negative associations (Hogg \& Terry, 2000). This is the case whether these differences are "real" or more stereotypical conceptions that do not necessarily correspond to organizational 
reality. Furthermore, such identification can lead to nationalistic confrontation shown in problems of cooperation (Olie, 1994) and politicization of integration processes (Vaara, 2003; Vaara, Tienari, \& Säntti, 2003b). Such relationships between firms can be seen as "arduous", which according to Szulanski (1996) is one of the main causes for the stickiness of knowledge. Such stickiness hampers knowledge transfer in international contexts. Also, perceived incompatibilities tend to be accentuated in politically sensitive settings. For example, Vaara, Tienari, and Björkman (2003a) found that in a Finnish-Swedish merger the Finns resisted Swedish dominance in knowledge transfer, and expressed their frustration in jokes such as "Best practice is West practice" (West referring to Sweden).

These arguments lead us to formulate the following hypothesis:

\section{Hypothesis 1a:}

National cultural differences are negatively associated with knowledge transfer in international acquisitions.

However, in addition to this conventional negative view, we wish to highlight the potential positive effects of national cultural differences on knowledge transfer. In the MNE context, literature on knowledge transfer suggests that deeper-level national cultural differences can be a major factor influencing knowledge transfer (Bhagat et al., 2002; Child \& Rodrigues, 1996; Kedia \& Bhagat, 1988). The key point is that particular national institutional environments have led to the development of specific knowledge stocks that are embedded in national culture and differ between countries (Barney, 1991). Therefore international acquisitions of companies in culturally distant countries increase the likelihood that the acquiring and the acquired firm will have different routines and repertoires and consequently different knowledge stocks. This is how Morosini et al. (1998) explained their finding that culturally more distant acquisitions outperform closer ones. Further, if the knowledge stocks of the acquiring and the acquired firms are different, they are likely to be less duplicative and more complementary - and thus increase knowledge transfer potential (Björkman et al., 2007; Shenkar, 2001). For example, the empirical study of Karim and Mitchell (2000) showed that acquisition of knowledge stocks that are different from existing ones helped the acquirers to develop new competencies or unique combinations with the existing knowledge. Therefore we suggest that national cultural differences are likely to contribute to increased knowledge transfer between the acquiring and the acquired firm. 


\section{Hypothesis 1b:}

National cultural differences are positively associated with knowledge transfer in international acquisitions.

\section{Organizational cultural differences}

In the context of M\&A, organizational cultural differences can be understood as differences in organization-specific beliefs, values, and practices between the acquiring and the acquired firm (Schein, 1990). The argument that organizational cultural differences are major causes of organizational problems, such as increased acculturative stress and change resistance, is a central part of research on M\&As (Buono, Bowditch, \& Lewis, 1985; Cartwright \& Cooper, 1996; Elsass \& Veiga, 1994; Nahavandi \& Malekzadeh, 1988; Sales \& Mirvis, 1984; Weber, 1996; Weber et al., 1996). Organizational problems have also been linked with a decreased level of organizational learning and knowledge transfer (Kamoche, 1997; Kang, Morris, \& Snell, 2007).

In addition, organizational cultural differences may imply a lack of trust between the employees of the acquiring and the acquired firms. McAllister (1995) suggests that if two groups are culturally different, members of one group are more likely to perceive the members of the other group as out-group members, and consequently as less trustworthy. Similarly, Williams (2001) links organizational cultural differences to over-identification and symbolic conflict - the perception that an out-group violates core in-group values. As a result, the practices of "one's own side" are valued to the extent that hostility towards "the other side" results (Williams, 2001). A lack of trust has been linked with the reluctance of economic actors to support each other (Fukuyama, 1996), with resistance to share knowledge (Nahapiet \& Ghoshal, 1998), and with decreased overall knowledge transfer (Abrams, Cross, Lesser, \& Levin, 2003). A lack of trust can also increase fear of exploitation (Renzl, 2008; Zaheer, McEvily, \& Perrone, 1998), which Empson (2000) identifies as an important reason for hostility to knowledge transfer on the part of employees. According to Empson (2000), another side of the same tendency is the fear of contamination: people are afraid that knowledge transfer from the other side will destroy their valued beliefs and practices. Hence, in contexts of apparent organizational cultural differences, employees will easily react negatively to cooperation in general and knowledge transfer in particular. 
Based on this argumentation, we propose the following:

\section{Hypothesis 2a:}

Organizational cultural differences are negatively associated with knowledge transfer in acquisitions.

However, recent acquisition studies have started to question and criticize the focus on the negative effects of organizational cultural differences. Newman and Chaharbagi (1998) criticized studies on organizational cultural differences for conceptualizing differences as negative. In addition, Riad (2005) warns that discursive elements in acquisition studies often demonize organizational culture through the association of difference with conflict. More importantly, Larsson and Finkelstein (1999) showed in their empirical study that organizational cultural differences - by contributing to complementary resources - can actually increase the potential for post-acquisition value creation. Furthermore, the analysis of Björkman et al. (2007), which does not distinguish between national and organizational cultural differences, provides support for the view that capabilities residing in national or organizational cultures can be a source of learning.

On this basis, we suggest that the association between organizational cultural differences and knowledge transfer could potentially be positive. If organizational cultural differences correspond to different but potentially complementary beliefs, values and practices, organizational cultural differences can contribute to knowledge transfer. Similarly, if specific organizational practices and related beliefs and values are clearly superior, then the difference in organizational cultures can be a direct source of positive knowledge transfer. Based on this logic, we propose the following:

\section{Hypothesis 2b:}

Organizational cultural differences are positively associated with knowledge transfer in acquisitions.

\section{Cultural Integration}

In addition to cultural differences, we have to focus on the dynamics of the integration process, which includes procedural, physical, and cultural integration (Shrivastava, 1986). 
We define organizational cultural integration as the development of organizational culture with compatible belief, value, and practice systems (Haspeslagh \& Jemison, 1991; Nahavandi \& Malekzadeh, 1988; Shrivastava, 1986). Thus cultural integration implies changes in either the acquiring or the acquired firm, or in both firms. However, the mechanisms of cultural integration require specification. Drawing on seminal research on cultural change (Ralston, 2008; Tung, 2008; Witt, 2008), we suggest two possible mechanisms through which cultural integration can take place: organizational cultural convergence and organizational cultural crossvergence. We further argue that both organizational cultural convergence and organizational cultural crossvergence are important facilitators for knowledge transfer in international acquisitions.

\section{Organizational cultural convergence}

On the macro level, Ralston et al. (1997) describe convergence as the process whereby the value systems of different countries become similar. Applying the convergence concept of Ralston et al. (1997) at a meso level, we suggest that organizational cultural convergence is a form of organizational cultural integration in which the organizational cultural differences are reduced. In the acquisition context, we understand cultural convergence as one culture - most often the culture of the acquired firm - becoming more similar than the other through postacquisition integration efforts.

Consistent with the literature of social community (Etzioni, 1961; Ouchi, 1980; Selznick, 1965), we argue that knowledge transfer will increase through cultural convergence. Cultural convergence facilitates communication between the organizational members from the acquiring and the acquired companies by reducing differences in assumptions and mental maps (Napier, Simmons, \& Stratton, 1989). Communication, in turn, reduces uncertainty and helps to create a favorable climate for knowledge transfer (Ranft \& Lord, 2002). In addition, the reduction of organizational cultural differences can also be a sign of developing trust between the previously separate organizations (Fukuyama, 1996). As explained above, this is a key issue, as trust has been linked to positive knowledge transfer outcomes in previous studies (Abrams et al., 2003; Nahapiet \& Ghoshal, 1998).

As a conclusion, we suggest that cultural distance-closing strategies resulting in organizational cultural convergence facilitate knowledge transfer in acquisitions precisely by 
removing organizational cultural differences that form impediments to knowledge transfer. Based on these arguments, we propose the following:

\section{Hypothesis 3:}

Organizational cultural convergence will be positively associated with knowledge transfer in acquisitions.

\section{Organizational cultural crossvergence}

At the macro level, Ralston et al. (1997) provide a definition for crossvergence as the development of new and unique belief and value systems, which is "something different" rather than something "in between" compared with the old value systems. Applying the concept of Ralston et al. (1997) to the meso level, we suggest that organizational cultural crossvergence is a form of organizational cultural integration that results in a new and unique organizational culture that is "something different" from the former cultures of both the acquiring and the acquired firm. Thus organizational cultural crossvergence is conceptually distinct from organizational cultural convergence. Understood in this way, organizational cultural crossvergence implies new identity-building in M\&A, which is defined as the creation of distinctive beliefs, values and norms characteristic of the new merged organization (Hogg \& Terry, 2000).

We suggest that organizational cultural crossvergence facilitates knowledge transfer in acquisitions. Generating a new shared identity between the merging firms through cultural crossvergence leads to the creation of greater interdependencies between the acquiring and acquired firms, which can facilitate the transfer of embedded knowledge (Birkinshaw, Bresman, \& Håkanson, 2000). Furthermore, through organizational cultural crossvergence, pre-merger realities, such as mutually negative stereotyping, are altered, and a new, jointly created social reality is reconstructed (Deal \& Kennedy, 1982; Larsson \& Lubatkin, 2001; Olie, 1994). As a result, organizational cultural crossvergence helps to create a climate of mutual understanding and trust in which less hostility is displayed towards the acquisition partner (Van Knippenberg \& Van Leeuwen, 2001). Finally, when the practices are new joint inventions and part of the new merged organization, they are more likely to be absorbed by both firms than if they were considered to originate from one acquisition party (Vaara et al., 2003a). Accordingly, we propose the following: 


\section{Hypothesis 4:}

Organizational cultural crossvergence will be positively associated with knowledge transfer.

\section{The Moderating Effect of National Cultural Differences in Cultural Integration}

There is reason, however, to assume that the positive effects of cultural integration are greatest precisely in the context of large national cultural differences. The point is that through cultural integration one creates a positive social dynamic for alleviating the risks of nationalistic confrontation, and for reaping the knowledge potential residing in distinctive national cultural systems. This can take place either by reducing organizational cultural differences that impede knowledge transfer (cultural convergence) or by creating a new platform for such transfer (cultural crossvergence).

Such a view finds support in previous studies. Hofstede (1980) already argued that when national cultural differences are high, a viable organization can be created through the development of a new organizational culture and identity. Similarly, Birkinshaw (1999) suggested that, as a general rule, the greater the national cultural differences, the better a "high road" approach to integration will work. The "high road" integration approach means the creation of a common culture before integrating the more technical parts of the acquiring and the acquired firms. Furthermore, Larsson and Lubatkin (2001) found that successful acculturation is possible even when national cultural differences are large, as long as the acquirer invests in formal and informal cultural integration. Thus, combining the theoretical arguments presented above, we argue that the positive effects of organizational cultural convergence and crossvergence on knowledge transfer will be greater in acquisitions where the national cultural differences are greater:

\section{Hypothesis 5:}

The positive association between organizational cultural convergence and knowledge transfer will be greater in acquisitions where the national cultural differences are greater.

\section{Hypothesis 6:}

The positive association between organizational cultural crossvergence and knowledge transfer will be greater in acquisitions where the national cultural differences are greater. 


\section{METHOD}

\section{Sample and Procedures}

This paper is based on our study of international acquisitions carried out by Finnish corporations. We collected our data through three mail surveys, the first covering the period 1993-1996, the second the period 1997-2000, and the third the period 2001-2004. The surveys were carried out in 1997, 2001, and 2005, 1-3 years after the acquisition had taken place. This time lag after the acquisition was chosen so as to allow for sufficient but not too long a time to have passed since the acquisition to examine the integration process outcomes in a meaningful way (Haspeslagh \& Jemison, 1991). In the final sample, the average time lag was 1.35 years. The data were collected across three time periods in order to obtain a large enough database for the analysis without letting too long a time pass between the time of the acquisition and the time of the survey. In the final sample, the data from each survey round were combined into a large cross-sectional database. ${ }^{1}$

The sample companies were selected from the database of the Finnish magazine Talouselämä on acquisitions carried out by Finnish firms from 1993 to 2004. The following four criteria were used in the selection of the acquisition cases. First, the acquirer had to be a Finlandbased company, excluding acquisitions made by Finnish subsidiaries. Second, management buy-outs and purely financial acquisitions were excluded, because they usually do not involve an integration process between two companies. Third, the Finnish acquiring party had to have a stock holding in excess of 50\%. Fourth, the acquired company's turnover had to exceed FIM 20 million (EUR3.4 million) so that the study would be able to concentrate on more significant acquisitions.

The data-gathering process was thorough and similar in all three survey rounds. First, letters were sent to the CEOs of the acquiring companies to inform them about the research project. Then the CEO or another top executive was contacted by telephone and asked to provide the names of key decision-makers from both the acquiring and acquired firms. This procedure helped to identify the right respondents from both the acquiring and acquired companies, ranging from one to five persons. Finally, the questionnaire was sent to the identified respondents, or the survey was completed with a telephone interview. It should be emphasized that we focused on ensuring that the actual key decision-makers involved in postacquisition integration responded to the questions rather than on maximizing the number of 
responses. In the cover letter, or at the beginning of the telephone interview, we provided general definitions of the key concepts of the study. ${ }^{2}$

Strict confidentiality was enforced to minimize social desirability bias and the pressure to provide "politically correct" answers. The respondents were assured that the answers would be handled confidentially so that no single cases or respondents would be pointed out. The respondents were also asked to send the questionnaires directly to the researchers to alleviate any pressure for political correctness. We therefore believe that the respondents felt relatively confident in providing answers that reflected their own perceptions of reality rather than any "official truth".

To check for face validity, the questionnaire was pre-tested on a group of academics and managers, and necessary changes were made. We also took several provisions to avoid pseudo-relationships between variables, and to minimize common method effects. For example, to overcome priming and consistency effects (Pfeffer \& Salancik, 1977), questions were scattered in the questionnaire, and other questions, not relevant to this analysis, were inserted between them. We found no evidence of common method bias related to our measures, since no single factor accounted for the majority of the covariance among the measures (Podsakoff, McKenzie, Lee, \& Podsakoff, 2003). The final survey questions are presented in Appendix B.

The average response rate in the surveys was 25\%. This compared well with the response rates in previous studies (Datta, 1991; Morosini et al., 1998), taking into account the confidential nature of acquisitions and the busy schedules of top managers. The three surveys resulted in a total number of 133 international acquisitions. On average, we received 1.77 answers per acquisition, resulting in a database of 236 answers. Of the answers, 175 were received from the acquirer side and 61 from the acquired firm side. The main reason for the lower number of answers from the latter was the high management turnover in the acquired firms. This led to a lower number of acquired firm managers who were qualified to answer the questionnaire regarding both the pre- and post-acquisition situation.

We have data from both the acquiring and the acquired managements for 44 acquisitions. In other multiple-response cases the responses are either from managers of the acquiring firm or from those of the acquired firm, but not from both. In all 44 cases in which we had responses from both the acquiring company and the acquired company management, we calculated 
intra-class correlations across the respondents for each of the 44 cases. The responses from both sides were highly correlated, ranging from 0.75 to 0.90 with an average of 0.83 . In addition, $t$-tests between the groups of acquiring and acquired firm responses across the 44 cases revealed no significant differences. These tests thus provide support for the reliability of our data.

We explored the possible impact of the respondents' background variables on our dependent variable, knowledge transfer, using individual level data. The frequency tables concerning these background variables are presented in Table A1 in Appendix A. In subsequent tests using regression analyses, none of the background variables were significant, which suggested that the respondent's gender, party (acquired/acquirer), status, previous experience, and involvement in the acquisition process had no significant impact on the respondent's evaluations concerning knowledge transfer.

Following an established method used in previous acquisition studies involving multiple respondents (Lubatkin, Calori, Very, \& Veiga, 1998; Lubatkin, Schweiger, \& Weber, 1999; Weber, 1996; Weber et al., 1996), we averaged the scores of multiple respondents to represent the general views of top management teams in acquisitions. Before averaging the scores of multiple respondents, we conducted several tests to ensure inter-rater reliability. The intra-class coefficients for each acquisition ranged from 0.75 to 0.93 with an average of 0.85. This suggests a reasonably high level of accord among all those responding for a specific acquisition. Similar criteria have been used in previous acquisition studies (Lubatkin et al., 1998, 1999).

The database included 133 international acquisitions. Out of the international acquisitions, 24 acquisitions were in Sweden, 21 in Germany, 13 in Estonia, 9 in Switzerland, 9 in the USA, 8 in Great Britain, 7 in Poland, 4 in Norway, 4 in Canada, 4 in France, 4 in Denmark, 3 in Lithuania, 3 in the Netherlands, 3 in China, 2 in South Africa, 2 in Belgium, 2 in Russia, 2 in Italy, 2 in Austria, and 1 acquisition each in Australia, Brazil, Columbia, Hungary, Latvia, Korea, and Romania.

Although this study focuses on international acquisitions of Finnish corporations, the findings are likely to be applicable beyond Finnish corporate acquisitions as well. The main reason is that Finland is well integrated with the European and worldwide economy. Consequently, international acquisitions by Finnish corporations are affected by most of the same trends as 
acquisitions worldwide. During the research period, such trends were related to the increasing importance of knowledge-based motives behind acquisitions, the growing importance of acquiring international service units for industrial companies, and the opening of formerly communist countries to foreign direct investment.

\section{Measures}

\section{Knowledge transfer}

We followed the example of previous studies on knowledge transfer in multinational companies (Zander, 1991) and in acquisitions (Bresman et al., 1999; Capron \& Mitchell, 1998; Ranft \& Lord, 2000). Our measures stem from our conceptual view of knowledge transfer as successful knowledge transfer, which implies a focus on the knowledge transfer benefits (Bresman et al., 1999). We were interested in the knowledge transfer benefits of the acquisition in general, without specifying the direction of the knowledge transfer (acquiring or acquired firm). One could argue that a closer look at the directions would have provided more insights into the actual processes of knowledge transfer, and their social and political dynamics. However, Bresman et al. (1999) found that distinguishing the direction of the knowledge transfer in acquisitions was not very useful, as those units with high levels of inward transfer also had a high level of outward transfer. Moreover, our purpose was to establish a reasonable measure of knowledge transfer to be able to examine how cultural differences (national and organizational) and cultural integration (convergence and crossvergence) explain such knowledge transfer.

We measured knowledge transfer as the mean of five questions concerning the extent to which knowledge transfer had resulted in benefits across the following organizational functions: management and control, sales and marketing, production, research and development, and finance. In general, a functional approach has been used in several knowledge transfer studies to measure knowledge transfer in different functions, which are then aggregated to a general measure of knowledge transfer (Björkman et al., 2004; Capron et al., 1998). Consequently, by "high level of knowledge transfer" we mean knowledge transfer that has resulted in many benefits across the acquiring and the acquired units, whereas by "low level of knowledge transfer" we mean knowledge transfer that has resulted in few benefits across the acquiring and the acquired units. 
The survey questions are provided in Appendix B. If the survey was conducted by mail, in the cover letter of the survey we asked the respondent to write "non-applicable" (N/A) next to any questions or sub-questions that were not applicable to his/her company. If the survey was conducted by a telephone interview, at the beginning of the interview the respondent was instructed to answer "non-applicable" if a question or a sub-question did not relate to his/her company. The researcher marked "N/A" next to such questions.

After the questionnaire was received, we conducted several reliability checks concerning the organizational functions. These reliability checks included:

(1) checking that the number of functions was the same across different questions (for instance, if the respondent indicated "N/A" next to a question concerning knowledge transfer in $R \& D$, we checked that he/she had also indicated "N/A" next to a question concerning cultural differences in R\&D);

(2) in multiple response cases, cross-checking the functions indicated by different respondents (for example, if respondent 1 for acquisition no. 10 indicated that R\&D was not applicable, we checked that respondent 2 for acquisition no. 10 also indicated that R\&D was not applicable); and

(3) checking that respondents to service industry acquisitions had indicated "N/A" next to $R \& D$ and production functions (the industries of the acquiring and the acquired firms were derived from the external Talouselämä database).

In those few cases where we found any inconsistency, the respondent was contacted by phone and asked to explain his/her answer. This resulted either in the clarification of obvious mistakes or in the removal of unclear answers.

By asking the respondents to indicate non-applicable functions, and then using the mean value of the functions that the firm actually had, we closely followed the approach of Björkman et al. (2004) in their analysis of knowledge transfer. Thus our knowledge transfer as well as the organizational cultural differences and convergence measures reflected the average across the applicable organizational functions. Importantly, to further test the reliability of our findings, we ran the regression analyses with a sample that included only firms that had all organizational functions, which led to results that were almost identical to those reported below. In addition, we conducted function-specific analyses that showed very similar results. 


\section{National cultural differences}

We measured national cultural distance by using the GLOBE practices scores (House et al., 2004). National cultural distance measures utilizing Hofstede's (1980) scores have been widely criticized (Harzing, 2003; McSweeney, 2002; Shenkar, 2001; Tayeb, 1994). The GLOBE project attempted to create more reliable national cultural differences scores. The extensive validity tests conducted for the GLOBE scores are reported in House et al. (2004). As opposed to Hofstede's four dimensions (uncertainty avoidance, power distance, individualism, masculinity) and later fifth dimension (long-term orientation), GLOBE scores have nine cultural dimensions: assertiveness, institutional collectivism, in-group collectivism, future orientation, gender egalitarianism, humane orientation, performance orientation, power distance, and uncertainty avoidance. GLOBE scores have been developed for both practices and values. We used the practices scores, since they are particularly relevant for postacquisition integration. Based on the nine dimensions of the GLOBE practices scores, we built a composite index of national cultural differences following the formula of Kogut and Singh (1988). Our index of national cultural differences represented the aggregate national cultural distance of the two acquisition parties:

$$
C D_{j}=\frac{\sum_{i=1}^{9}\left[\left(I_{i j}-I_{i f}\right)^{2} / V_{i}\right]}{9}
$$

where $C D j$ is the cultural difference for the $j$ th country; $I_{i j}$ is the Globe score for the $i$ th cultural dimension and $j$ th country; $f$ indicates Finland; and $V_{i}$ is the variance in the Globe score index of the $i$ th dimension.

We conducted several additional tests by using alternative measures for national cultural differences, including the measures of Hofstede (1991), Trompenaars and Hampden-Turner (1998), and Inglehart et al. (2004). The use of alternative measures led to results that were essentially similar to those obtained with the GLOBE scores, and thus supported the general validity of GLOBE scores as measures of national cultural differences. ${ }^{3}$

\section{Organizational cultural differences}


Following the example of previous acquisition studies (Chatterjee et al., 1992; Lubatkin et al., 1999; Weber, 1996; Weber et al., 1996), we measured perceptions of organizational cultural differences rather than examine the more tangible and objective outcomes of organizational culture such as reward structures or mission statements. According to Chatterjee et al. (1992), the advantage of perceptional measures is that perceptions are likely to be better predictors of behavior. The more dissimilar the acquisition partner is perceived to be, the stronger the negative feelings in-group members are likely to hold towards the acquisition partner that is considered to be out-group (Elsass \& Veiga, 1994).

We asked managers to describe the extent of cultural differences across key organizational functions. These included management and control, sales and marketing, production, research and development, and finance. In addition, we asked managers to describe differences in company values in general, and differences in the values of key decision-makers. The survey questions are provided in Appendix B. The mean value of these questions was used to represent overall organizational cultural differences. As explained above (see "knowledge transfer"), we conducted elaborate reliability checks to make sure that the answers to specific questions about the functions made sense.

This approach means that managers retrospectively evaluated the organizational cultural differences prior to the acquisition between the acquiring and the acquired firms. It can be argued that the differences should be measured at the time the acquisition is completed. However, gaining access to the firms at that time is extremely difficult. We also maintain that managers are able to recall the pre-acquisition situations reasonably well, because acquisitions have the affect of sharpening rather than dulling memory. Furthermore, learning about actual organizational cultural differences as opposed to stereotypical assumptions takes time, which suggests that the assessment should take place after real experiences of the integration efforts.

\section{Cultural convergence}

To our knowledge, only Birkinshaw et al. (2000) have previously measured cultural convergence in the acquisition context. The goal of Birkinshaw et al. (2000) was to establish whether there was any measurable cultural convergence between the acquiring and the acquired firms. Similar to Birkinshaw et al. (2000), we felt that the question of whether we 
were measuring exactly the "right" dimensions of culture was less important than whether we were able to reliably tap into a change in our chosen dimensions.

Birkinshaw et al. (2000) adapted Hofstede's (1991) measures on organizational culture to fit their context of exploring knowledge transfer in research and development units. Because we did not only focus on R\&D knowledge, the measure of Birkinshaw et al. (2000) was not directly applicable to our study. We chose to use a functional approach in which we measured organizational cultural differences across different organizational functions, and additionally explored differences in the values and in the values of the decision-makers. The organizational functions corresponded to the functions used in our knowledge transfer measure.

In separate questions, the respondents were first asked to evaluate organizational cultural differences before the acquisition, and then to evaluate organizational cultural differences after the acquisition at the time of the survey (see Appendix B). The respondents answered both questions separately along seven organizational dimensions (management and control, sales and marketing, production, $\mathrm{R} \& \mathrm{D}$, finance, company values in general, values of decision-makers). As explained above (see "knowledge transfer" and "organizational cultural differences"), we conducted reliability checks to make sure that the answers to specific questions about the functions made sense.

To capture the convergence in organizational cultural differences during the integration process, we calculated the change between cultural differences before the acquisition and cultural differences at the time of the survey along the seven functional and value dimensions:

$$
C C=\sum\left(O C D_{\text {before }}\right)-\sum\left(O C D_{\text {after }}\right)
$$

where $C C$ is organizational cultural convergence corresponding to the change in organizational cultural differences; $O C D_{\text {before }}$ is organizational cultural differences before the acquisition across different organizational functions and values; and $O C D_{\text {after }}$ is organizational cultural differences at the time of the survey across different organizational functions and values.

The variables describing cultural convergence along different organizational dimensions were then entered into an exploratory factor analysis using principal component analysis with 
varimax rotation (see Table 1). The convergent validity of the construct was good, with factor loadings ranging from 0.598 to 0.784 . The construct was also clearly distinct from the construct of organizational cultural crossvergence. The resulting factor scores for "organizational cultural convergence" were used in the following regression analyses.

\section{Organizational cultural crossvergence}

This side of cultural integration has received some attention in earlier qualitative acquisition studies (Mirvis \& Marks, 1992a, 1992b; Van Knippenberg \& Van Leeuwen, 2001). However, to the best of our knowledge, it has not been measured in previous quantitative acquisition studies. Although our conceptualization of organizational cultural crossvergence is derived from Ralston et al. (1997), their measurement of cultural convergence was at the national cultural level, and therefore not applicable to our context. Because no existing measure was available from the literature, we derived our questions from previous qualitative literature on cultural integration (Elsass \& Veiga, 1994; Mirvis \& Marks, 1992a, 1992b; Nahavandi \& Malekzadeh, 1988), and from in-depth background interviews and subsequent generation, pretesting, and refinement of items. The organizational cultural crossvergence construct was based on three questions concerning the extent to which a new culture, new identity, and new practices shared by both companies had been created after the acquisition (see Appendix B). The respondents answered each question on a Likert scale from 1 to 7 , where 1 corresponded to "not at all" and 7 to "very much". Based on the exploratory factor analyses, organizational cultural crossvergence was clearly a different cultural dimension from organizational cultural convergence (see Table 1). The resulting factor scores for organizational cultural convergence were used in the following regression analyses. ${ }^{4}$

Table 1 Results of the explanatory factor analysis: cultural convergence and cultural crossvergence

\begin{tabular}{|l|l|l|}
\hline Variable & Cultural convergence & Cultural crossvergence \\
\hline Cultural change in management and control & $\mathbf{0 . 7 8 4}$ & -0.069 \\
\hline Cultural change in sales and marketing & $\mathbf{0 . 7 4 4}$ & 0.141 \\
\hline Cultural change in research and development & $\mathbf{0 . 6 5 3}$ & 0.059 \\
\hline Cultural change in production & $\mathbf{0 . 6 6 6}$ & 0.140 \\
\hline Cultural change in finance & $\mathbf{0 . 5 9 8}$ & -0.133 \\
\hline Cultural change in company values in general & $\mathbf{0 . 6 8 4}$ & 0.062 \\
\hline Cultural change in decision-makers' values & $\mathbf{0 . 7 6 0}$ & 0.062 \\
\hline Creation of a new shared culture & -0.078 & $\mathbf{0 . 8 6 7}$ \\
\hline
\end{tabular}




\begin{tabular}{|l|l|l|}
\hline & & \\
\hline Creation of a new shared identity & -0.057 & $\mathbf{0 . 8 9 8}$ \\
\hline Creation of new shared practices & 0.190 & $\mathbf{0 . 3 8 5}$ \\
\hline $\begin{array}{l}\text { Rotated component matrix. } \\
\text { Extraction method: Principal component analysis. } \\
\text { Rotation method: varimax with Kaiser normalization. } \\
\text { Rotation converged in three iterations. } \\
\text { The bold values represent the highest factor loadings. }\end{array}$ \\
\hline
\end{tabular}

\section{Control Variables}

Size

Following previous acquisition studies (Haleblian \& Finkelstein, 1999; Kusewitt, 1985; Larsson \& Finkelstein, 1999; Morosini et al., 1998), we controlled for the size of the acquisition. We measured this as the turnover by the acquired company at the time of acquisition using external data from the database of the financial magazine Talouselämä.

\section{Industry}

Following Larsson and Lubatkin (2001) and Pablo (1994), we controlled for the service sector effect by using a dummy variable to indicate whether the acquisition was in the service industry ( 1 =service industry, $0=$ others), using external data from the Talouselämä database.

\section{Time elapsed}

Time elapsed since acquisition could affect the outcome of acquisitions (Greenwood, Hinings, \& Brown, 1994; Very et al., 1997). Bresman et al. (1999) found empirical evidence that knowledge transfer in acquisitions was positively related to time elapsed since acquisition. Given that our data were collected from 1 to 3 years after acquisition, we controlled for possible temporal variance by recording the age of the merger as the number of years $(1,2$, or 3 ), which transpired from the time of the merger to the time that we received the completed questionnaire (Very et al., 1997). We used external data from the Talouselämä database.

\section{Operational integration effort}

To ensure that our analysis of convergence and crossvergence would not be affected by the integration approach (Haspeslagh \& Jemison, 1991), we controlled for two essential dimensions of integration approach: operational integration and organizational autonomy. 
Adapting the items used in previous studies (Larsson \& Lubatkin, 2001; Lubatkin et al., 1998; Morosini et al., 1994; Weber et al., 1996), our operational integration effort construct is based on targeted questions measuring the level of effort in operational integration activities. The respondents were asked about:

(1) the extent of post-acquisition changes in the acquiring company;

(2) the extent of post-acquisition changes in the acquired company;

(3) the extent to which overlapping between the units had been eliminated during postacquisition integration; and

(4) the extent to which practices had been standardized.

\section{Organizational autonomy}

Adapting the items used in previous research (Larsson \& Finkelstein, 1999; Morosini et al., 1998; Very et al., 1997), we measured post-acquisition organizational autonomy by asking the respondents the level of control under which the acquired firm had been operating after the acquisition, ranging from 1=extremely tight control to 7=fully independently. In addition, we measured the extent to which the values of the acquirer had dominated the integration decisions (from $1=$ very much to $7=$ not at all). Furthermore, we asked the respondents the extent to which the changes had been based on the acquired firm's practices. Finally, we asked whether the management of the acquirer or the management of the acquired firm had dominated the integration decisions. A mean of these questions measured the amount of autonomy given to the acquired firm. An exploratory factor analysis showed that operational integration effort and organizational autonomy loaded on different factors. This suggested that they were two distinct dimensions of post-acquisition integration.

\section{RESULTS}

We examined the correlation matrix to identify any collinearity between the variables in our model. The correlation table suggested no serious collinearity problems (Hair, Anderson, Tatham, \& Black, 1998) (see Table 2). Also, the values of variance inflation factors (VIFs) remained under the recommended limit of eight in all models (see Table 3).

To discern the effects of independent and control variables in international acquisitions, as well as to make a distinction between direct and interaction effects, we used hierarchical 
regression analysis to estimate four regression models (see Table 3). In Model 1 we tested the effect of control variables. In Model 2 we introduced cultural differences to test Hypotheses 1a, 1b, 2a, and 2b. Cultural integration variables were included in Model 3 to test Hypotheses 3 and 4. Finally, in Model 4 we tested our interaction hypotheses (Hypotheses 5 and 6). All models were statistically significant. 
Table 2 Descriptive statistics and correlations for the dependent variable (knowledge transfer), independent and control variables

\begin{tabular}{|c|c|c|c|c|c|c|c|c|c|c|c|c|c|}
\hline Variables & Mean & s.d. & 1 & 2 & 3 & 4 & 5 & 6 & 7 & 8 & 9 & 10 & 11 \\
\hline 1 Knowledge transfer & 4.463 & 1.028 & 1.000 & & & & & & & & & & \\
\hline 2 Size & 83.449 & 209.465 & $0.158 w$ & 1.000 & & & & & & & & & \\
\hline 3 Industry & 0.158 & 0.366 & -0.101 & $\begin{array}{c}- \\
0.008\end{array}$ & 1.000 & & & & & & & & \\
\hline 4 Time elapsed & 2.744 & 1.257 & -0.107 & $\begin{array}{c}- \\
0.016\end{array}$ & $0.207^{*}$ & 1.000 & & & & & & & \\
\hline 5 Operational integration effort & 4.273 & 0.912 & $0.277^{* *}$ & 0.062 & $0.195^{*}$ & 0.013 & 1.000 & & & & & & \\
\hline 6 Autonomy & 2.000 & 0.952 & $0.314^{* * *}$ & 0.009 & 0.025 & $0.181 *$ & $-0.150 *$ & 1.000 & & & & & \\
\hline 7 National cultural differences & 0.498 & 0.158 & $0.279 * *$ & $\begin{array}{c}- \\
0.114\end{array}$ & -0.110 & -0.055 & 0.030 & 0.009 & 1.000 & & & & \\
\hline $\begin{array}{l}8 \text { Organizational cultural } \\
\text { differences }\end{array}$ & 4.929 & 0.792 & $0.235^{* *}$ & $\begin{array}{c}- \\
0.076\end{array}$ & $0.174^{*}$ & 0.015 & $0.255^{* *}$ & $\begin{array}{c}- \\
0.337^{* * *}\end{array}$ & $0.135 w$ & 1.000 & & & \\
\hline $\begin{array}{l}9 \text { Organizational cultural } \\
\text { convergence }\end{array}$ & 0.000 & 1.000 & $0.386 * * *$ & $\begin{array}{c}- \\
0.071\end{array}$ & $0.156^{*}$ & $0.175^{*}$ & $0.374 * * *$ & $\begin{array}{c}- \\
0.449 * * *\end{array}$ & 0.026 & $0.547^{* * *}$ & 1.000 & & \\
\hline $\begin{array}{l}10 \text { Organizational cultural } \\
\text { crossvergence }\end{array}$ & 0.000 & 1.000 & $0.150 w$ & 0.029 & 0.048 & 0.091 & $0.247^{* *}$ & $0.265^{* *}$ & 0.024 & 0.019 & 0.000 & 1.000 & \\
\hline $\begin{array}{l}11 \text { Organizational cultural } \\
\text { convergence x national cultural } \\
\text { differences }\end{array}$ & -0.025 & 0.536 & $0.415^{* * *}$ & $0 . \overline{066}$ & 0.053 & 0.137 & $0.260 * *$ & $\begin{array}{c}- \\
0.546 * * *\end{array}$ & -0.064 & $0.593 * * *$ & $0.893 * * *$ & -0.043 & \\
\hline $\begin{array}{l}12 \text { Organizational cultural } \\
\text { crossvergence x national cultural } \\
\text { differences }\end{array}$ & -0.003 & 0.519 & $0.143 w$ & 0.048 & -0.015 & 0.086 & $0.179 *$ & $0.291 * *$ & -0.091 & -0.063 & -0.044 & $0.885^{* * *}$ & -0.115 \\
\hline
\end{tabular}

All two-tailed tests: w po0.10; *po0.05; **po0.01; ***po0.001.

The mean and standard deviation for organizational cultural convergence and organizational cultural crossvergence are based on factor scores from explorative factor analysis with varimax rotation.

The correlation between organizational cultural convergence and organizational cultural crossvergence is zero because of varimax rotation. 
Table 3 Results of the hierarchical regression analysis: The impact of cultural differences and cultural integration on the dependent variable of knowledge transfer in international

\begin{tabular}{|c|c|c|c|c|c|c|c|c|c|c|c|c|c|c|c|c|}
\hline & \multicolumn{4}{|c|}{ Model 1: Control variables } & \multicolumn{4}{|c|}{ Model 2: Cultural differences } & \multicolumn{4}{|c|}{ Model 3: Cultural integration } & \multicolumn{4}{|c|}{ Model 4: Interaction variables } \\
\hline & Beta & $t$ & Sig. & VIF & Beta & $t$ & Sig. & $V I F$ & Beta & $t$ & Sig. & VIF & Beta & $t$ & Sig. & $V I F$ \\
\hline \multicolumn{17}{|l|}{ Control variables } \\
\hline Size & -0.141 & -1.493 & 0.139 & 1.004 & -0.110 & -1.191 & 0.237 & 1.020 & -0.113 & -1.269 & 0.208 & 1.024 & -0.105 & -1.237 & 0.219 & 1.026 \\
\hline Industry & -0.152 & -1.542 & 0.126 & 1.088 & -0.135 & -1.385 & 0.170 & 1.125 & -0.128 & -1.379 & 0.171 & 1.125 & -0.033 & -0.347 & 0.729 & 1.261 \\
\hline Time elapsed & -0.032 & -0.326 & 0.475 & 1.084 & -0.026 & -0.276 & 0.784 & 1.089 & -0.100 & -1.047 & 0.298 & 1.188 & -0.131 & -1.491 & 0.160 & 1.206 \\
\hline Operational integration effort & $0.257 *$ & 2.640 & 0.010 & 1.067 & $0.233 *$ & 2.415 & 0.018 & 1.107 & 0.110 & 1.101 & 0.274 & 1.300 & $0.164 \mathrm{w}$ & 1.681 & 0.097 & 1.352 \\
\hline Autonomy & $-0.272 * *$ & -2.795 & 0.006 & 1.061 & $-0.253^{*}$ & -2.539 & 0.013 & 1.187 & $-0.218^{*}$ & -2.024 & 0.046 & 1.517 & -0.128 & -1.158 & 0.250 & 1.745 \\
\hline \multicolumn{17}{|l|}{ Cultural differences } \\
\hline National cultural differences & & & & & $0.235 *$ & 2.499 & 0.014 & 1.056 & $0.240 * *$ & 2.658 & 0.009 & 1.057 & $0.361 * * *$ & 3.813 & 0.000 & 1.273 \\
\hline $\begin{array}{l}\text { Organizational cultural } \\
\text { differences }\end{array}$ & & & & & 0.074 & 0.722 & 0.472 & 1.248 & -0.050 & -0.463 & 0.644 & 1.527 & -0.137 & -1.240 & 0.218 & 1.737 \\
\hline \multicolumn{17}{|l|}{ Cultural integration } \\
\hline $\begin{array}{l}\text { Organizational cultural } \\
\text { convergence }\end{array}$ & & & & & & & & & $0.297^{*}$ & 2.450 & 0.016 & 1.915 & -0.194 & -0.904 & 0.369 & 6.558 \\
\hline $\begin{array}{l}\text { Organizational cultural } \\
\text { crossvergence }\end{array}$ & & & & & & & & & $0.195^{*}$ & 2.034 & 0.045 & 1.191 & -0.207 & -1.050 & 0.297 & 5.541 \\
\hline \multicolumn{17}{|l|}{ Interaction variables } \\
\hline $\begin{array}{l}\text { convergence x National } \\
\text { cultural differences }\end{array}$ & & & & & & & & & & & & & $0.634 * *$ & 2.686 & 0.009 & 7.909 \\
\hline $\begin{array}{l}\text { Organizational cultural } \\
\text { crossvergence x National } \\
\text { cultural differences }\end{array}$ & & & & & & & & & & & & & $0.439 *$ & 2.229 & 0.029 & 5.508 \\
\hline \multicolumn{17}{|l|}{ Model statistics } \\
\hline $\mathrm{R}$ & 0.445 & & & & 0.511 & & & & 0.582 & & & & 0.639 & & & \\
\hline R2 & 0.198 & & & & 0.261 & & & & 0.339 & & & & 0.408 & & & \\
\hline Adjusted R2 & 0.153 & & & & 0.202 & & & & 0.270 & & & & 0.330 & & & \\
\hline Incremental R2 & 0.198 & & & & 0.063 & & & & $0.078 * *$ & & & & $0.069 * *$ & & & \\
\hline $\mathrm{F}$ & $4.433 * *$ & & & & $4.436 * *$ & & & & $4.906 * * *$ & & & & $5.260 * * *$ & & & \\
\hline
\end{tabular}

All two-tailed tests. wpo0.10; *po0.05; **po0.01; ***po0.001.

Data in the table represent standardized beta

coefficients.

Dependent variable: Knowledge

transfer. 
As to the hypotheses regarding organizational cultural differences (Hypotheses $1 \mathrm{a}$ and $1 \mathrm{~b}$ ), we found support for the proposition that national cultural differences were positively associated with knowledge transfer (Model 2, $\beta=0.235^{*}$; Model 3, $\beta=0.240^{* *}$; Model 4, $\beta$ $\left.=0.361^{* * *}\right)$. Regarding Hypotheses $2 \mathrm{a}$ and $2 \mathrm{~b}$, organizational cultural differences were not related to knowledge transfer. The non-significant effect was consistent across all our models, and thus neither Hypothesis 2a nor Hypothesis 2b gained support. Our prediction in Hypothesis 3 that organizational cultural convergence would be positively associated with knowledge transfer was supported (Model 3, $\beta=0.297^{*}$ ). Consistent with our Hypothesis 4, the association between organizational cultural crossvergence and knowledge transfer was positive and significant (Model 3, $\beta=0.195^{*}$ ). In Hypothesis 5 we suggested that the positive association of cultural convergence and knowledge transfer would be greater in acquisitions that are characterized by large national cultural differences. We found strong support for this hypothesis, as demonstrated by a positive and significant interaction term of organizational cultural convergence and national cultural differences ( $\beta=0.634^{* *}$ ). Similarly, Hypothesis 6 proposed that the positive association of organizational cultural crossvergence and knowledge transfer would be greater in acquisitions that are characterized by large national cultural differences. This hypothesis was supported by the data $\left(\beta=0.439^{*}\right)$.

As to control variables, the variables measuring size, industry, and time elapsed since acquisition were not significant. Operational integration effort was positively associated with knowledge transfer, but the effect diminished as cultural variables were introduced to the analysis (Model 1, $\beta=0.257^{*}$; Model 2, $\beta=0.233^{*}$; Model 3, $\beta=0.110$; Model 4, $\beta$ $\left.=0.164^{[\text {dagger] }}\right)$. Autonomy was negatively associated with knowledge transfer, although the relationship weakened as cultural variables were entered into the analysis (Model 1, $\beta=$ =$0.272^{* *}$; Model 2, $\beta=-0.253^{*}$; Model 3, $\beta=-0.218^{*}$; Model 4, $\beta=-0.128$ ).

\section{DISCUSSION AND CONCLUSION}

Despite a proliferation of studies taking a cultural perspective on M\&As (Chatterjee et al., 1992; Datta, 1991; Weber et al., 1996), we still lack understanding of the role that cultural differences and cultural integration variables play in knowledge transfer in international acquisitions. Hence the purpose of this study has been to examine the impact of both cultural differences (national and organizational) and cultural integration (convergence and crossvergence) on knowledge transfer in post-acquisition integration. Capturing the cultural dynamics is difficult, as one is dealing with phenomena constructed by the organizational 
members when decisions concerning organizational changes are being made. We believe, however, that our analysis contributes to previous research in two important senses: by confirming that national cultural differences provide great potential for knowledge transfer; and by showing that cultural integration in the form of organizational cultural convergence and cultural crossvergence is crucial in such knowledge transfer.

Our starting point was to conceptualize national cultural differences as deeper-level cultural manifestations. In addition to the conventional view that emphasizes the negative effects of national cultural differences (Olie, 1994; Vaara, 2003; Weber et al., 1996), we suggested that national cultural differences could also have positive effects. International acquisitions of companies in culturally distant countries could increase the likelihood that the acquiring and the acquired firm will have different routines and repertoires, and consequently different knowledge stocks. We further argued that different knowledge stocks of the acquiring and the acquired firms are likely to be less duplicative and complementary (Björkman et al., 2007; Larsson \& Finkelstein, 1999; Shenkar, 2001), and thereby contribute to knowledge transfer benefits through increased knowledge transfer potential. We found clear support for the positive relationship between national cultural differences and knowledge transfer. Our finding means that international acquisitions of companies in culturally distant countries do not necessarily have negative performance implications, but can have clear positive results in terms of increased knowledge transfer. This further implies that culturally distant international acquisitions can be particularly useful for upgrading the firm's existing knowledge stock. Through this finding, our study contributes to the small but growing group of studies that have linked national cultural differences to positive value creation in acquisitions (Björkman et al., 2007; Chakrabarti et al., 2009; Hébert et al., 2005; Larsson \& Finkelstein, 1999; Morosini et al., 1998).

We further proposed that organizational cultural differences - as more surface-level cultural aspects - also have an effect on knowledge transfer. Following previous research (Buono et al., 1985; Cartwright \& Cooper, 1996; Elsass \& Veiga, 1994; Sales \& Mirvis, 1984; Weber, 1996), we argued that organizational cultural differences could act as impediments to knowledge transfer, and would thus be negatively associated with knowledge transfer in international acquisitions. However, we also put forth an alternative hypothesis according to which organizational cultural differences - like national cultural differences - can be a source of knowledge transfer potential (Larsson \& Finkelstein, 1999). Interestingly, organizational 
cultural differences had no significant effect on knowledge transfer in our empirical analysis. One possible interpretation is that organizational cultural differences could have both negative and positive effects, as suggested by our Hypotheses 2a and 2b. Taken together, these dual effects could cancel each other out, resulting in an insignificant relationship. Another possibility is that we were unable to discover the full effect of organizational cultural differences because of the limitations of our measure. Therefore the insignificant result does not mean that we should discard the role of organizational cultural differences in the knowledge transfer process. Instead, it implies that the relationship requires further investigation through construct development and specification of different impact mechanisms.

Although organizational cultural differences as such had no significant effect on knowledge transfer, cultural integration variables were important determinants of knowledge transfer in our analysis. This may appear contradictory at first glance, but implies that the effect of organizational cultural differences on knowledge transfer depends on how the organizational relationships develop over time, and on how the integration process is managed (Haspeslagh \& Jemison, 1991). This result is interesting, as it implies that we should look beyond organizational cultural differences into the processes of cultural integration to understand how knowledge is transferred.

In fact, the most important contribution of this analysis is that it sheds more light on the crucial role of cultural integration variables. By drawing on previous work on cultural change (Ralston, 2008; Tung, 2008), we distinguished two dimensions of cultural integration: cultural convergence (the reduction of cultural differences) and cultural crossvergence (the creation of new corporate culture). We proposed that cultural convergence has a positive impact on knowledge transfer through processes such as facilitated communication, reduced uncertainty, and increased trust. We found strong support for this positive effect. The finding implies that cultural dynamics that reduce organizational cultural differences are the key to successful knowledge transfer. This is theoretically interesting, because it signifies that one should focus on the dynamics of cultural conceptions in addition to static indicators of difference. We also proposed that organizational cultural crossvergence has a positive impact on knowledge transfer through the creation of greater interdependencies, mutual understanding, and joint practices. Our empirical results clearly support this view. This is a significant finding, as it confirms that investing in the creation of new culture - which is 
"something different" rather than something "in between" the previous cultures - contributes to knowledge transfer.

We further argued that the positive effects of organizational cultural convergence and crossvergence are greatest precisely in the context of potentially beneficial national cultural differences. This is because cultural integration creates a positive social dynamic for alleviating the potential problems of national confrontation and reaping the knowledge potential residing in the diverse beliefs, values and practices embedded in specific national contexts. The empirical results showed that this is indeed the case for both cultural convergence and crossvergence - at least in this sample of acquisitions. This is an important finding, as it elucidates the linkage between the potential residing in international acquisitions (captured by the notion of "national cultural differences") and the sociocultural dynamic needed to reap such benefits (captured by organizational "cultural convergence" and "crossvergence"). This result is theoretically significant, as it provides a new, dynamic view on the complex relationship between cultural differences and post-acquisition integration. But it also has practical implications by demonstrating that the management of cultural integration matters.

Furthermore, the results related to two of our control variables, operational integration effort and organizational autonomy, offer interesting insights. Concerning operational integration effort, as expected on the basis of prior studies (Björkman et al., 2007; Haspeslagh \& Jemison, 1991), we found that operational integration effort had a positive impact on knowledge transfer. However, the relationship weakened as cultural variables were added to the model. Rather than undermining the importance of operational integration, the result suggests that the complex relationship between operational and cultural integration is one of the key issues to be examined in more detail in future studies. Regarding organizational autonomy, previous studies have suggested that knowledge-intensive acquisitions may need to be managed through a preservation mode, which corresponds to a high level of autonomy, at least for a period of time (Haspeslagh \& Jemison, 1991; Porrini, 2004; Ranft \& Lord, 2002). However, our analysis suggests that autonomy may also restrict the level of knowledge transfer in such acquisitions. How exactly the need of autonomy is related to operational and cultural integration forms another topic for future research in this area.

Overall, the results of our analysis raise an intriguing question: why does organizational cultural convergence occur in some acquisitions, crossvergence in others, and no cultural 
integration or divergence in still others? We think that this crucial question can be better understood by carefully analyzing the link between different post-acquisition integration modes and cultural integration mechanisms. We suggest that cultural convergence is likely to take place particularly in "absorption" (Haspeslagh \& Jemison, 1991) or "assimilation" (Nahavandi \& Malekzadeh, 1988) acquisitions, in which the objective is to dissolve the boundary between the acquiring and the acquired firms. In such cases, focusing on the reduction of organizational cultural differences through convergence would be the appropriate and most effective way to enhance integration and knowledge transfer. In other cases, such as "symbiosis" (Haspeslagh \& Jemison, 1991) or "integration" (Nahavandi \& Malekzadeh, 1988), the acquiring and the acquired firms coexist and gradually become increasingly interdependent. Thus one could assume that these acquisitions would be characterized by the construction of new and unique organizational culture - that is, organizational cultural crossvergence. In still other cases, such as "preservation" (Haspeslagh \& Jemison, 1991) or "separation" (Nahavandi \& Malekzadeh, 1988), the acquisition is managed at arm's length, and the culture of the acquired firm remains different from that of the acquiring firm, or may even become increasingly different over time as both firms continue to evolve separately. In these cases one would expect to see no cultural change, or cultural divergence. Whether and to what extent one can distinguish such linkages between post-acquisition integration modes and cultural integration mechanisms is a question that should be empirically explored in detail in future research.

In addition to such analysis of integration modes, a more in-depth understanding of convergence, crossvergence and divergence requires close analysis of specific managerial actions. Based on previous studies, we know that communication (Schweiger \& DeNisi, 1991), investments in cooperation (Schweiger \& Goulet, 2005), use of expatriates (Hébert et al., 2005), sociocultural training (Vaara et al., 2003a), and identity-building campaigns (Vaara, Tienari, \& Irrmann, 2007) contribute to cultural integration. However, there is a need to analyze in more detail how exactly such actions contribute to convergence and/or crossvergence. Furthermore, managerial actions - even well intended ones - can also increase cultural confrontation and lead to divergence in the turmoil of post-acquisition integration (Empson, 2001). An educated guess is that the effects of specific managerial actions on cultural integration can be complex and contradictory. Also, managerial actions may be influenced by the national cultural background of individual managers. For instance, the national cultural differences between the values of the CEOs of the acquiring and acquired 
firms may be relevant and different from the national cultural differences at the firm level. Therefore new targeted studies that integrate national, organizational, and individual levels of analyses are needed. At the individual level, the focus could be on the CEOs, top management group, or middle managers.

This study has its limitations, which should be taken seriously. It is possible that our sample has some unique features, and that other data would lead to somewhat different results. Furthermore, our analysis is based on cross-sectional data, and suffers from the limitations of this kind of research design. One of the key issues is causality. We cannot be sure that it is cultural integration that influences knowledge transfer, rather than vice versa. For example, higher levels of knowledge transfer could facilitate the reduction of perceived cultural differences by informing the members of acquiring and acquired firms about each other's practices, beliefs, and values. Also, the knowledge transfer process might decrease cultural barriers, because it relies on communication between different groups. In the end, however, such reservations do not undermine the importance of our findings. The point is that knowledge transfer in international acquisitions seems to require cultural integration in the form of cultural convergence or crossvergence. The crucial issue in the message we are sending is not which is the chicken and which is the egg, but rather that successful knowledge transfer is associated with cultural integration.

Another key limitation is the post hoc longitudinal comparison approach of this study. When measuring organizational cultural convergence and crossvergence, we asked our respondents to make post hoc longitudinal comparisons by describing the change in culture. Future studies should consider using a true longitudinal approach and collect the pre-acquisition data immediately after the acquisition, and the post-acquisition data, for instance, 3 years later. This should be combined with the use of more elaborate measures of organizational culture, such as the organizational cultural types of Cameron and Quinn's (2006) value-based framework or other similar measures discussed by Ashkanasy, Wilderom, and Peterson (2000). If the researchers had longitudinal pre-acquisition and post-acquisition measures of organizational culture types for both the acquiring and the acquired firms, they could determine the longitudinal convergence, crossvergence, or divergence of organizational cultures, as well as the degree and direction of cultural integration.

With the exception of national cultural differences, our data are based on the subjective responses of the key decision-makers, which implies a risk of common method bias. Our tests 
did not indicate such problems, but our results should be read with these concerns in mind. In addition, our focus on the top levels of hierarchy means that the views of top managers may differ, for example, from those of the operating staff. Additionally, our survey - despite measures taken to alleviate such tendencies - may suffer from other response biases: for example, over-optimism or retrospective recall. It is also worth noting that our respondents did not have full anonymity, because we wanted to have the option to contact the respondents after the survey in order to qualitatively study the most interesting acquisition cases in more detail. However, we believe that the bias of providing politically correct answers was reduced by the confidentiality of the survey. The respondents were assured of the confidentiality of the survey, and of the fact that no individual acquisition cases would be singled out in any part of our analysis.

While we go further than many previous acquisition studies by including responses from both the acquiring and the acquired firms, the low response rate from the acquired firms can be considered a limitation of this study. This is an important aspect to consider in future research designs. We targeted respondents from the acquired firms that had knowledge of both the pre- and post-acquisition situation, but high top management turnover in the acquired firms complicated this endeavor. A possibility for future research is to widen the focus from the top management level to include lower-level managers and employees in order to increase the response rate from the acquired firm.

Finally, it is important to acknowledge the limitations of our measures. Using general terms such as "knowledge transfer" and "cultural differences" may have injected some extraneous variance in the results. Also, our knowledge transfer measure is limited to the extent to which it captures the complexity of the phenomenon at hand. For instance, our measure focuses on the benefits of knowledge transfer in a particular acquisition, but does not distinguish the direction of the knowledge flows or the specific type of knowledge that is being transferred (e.g., tacit vs explicit, marketing vs technical knowledge), or the level of organizational embeddedness of knowledge. An additional difficulty related to measuring knowledge transfer is that, while the term "knowledge transfer" is widely used in the literature, scholars use many different definitions and measurements of the term, and practitioners can interpret its meanings in various ways. Consequently, there is a danger of apples-to-oranges comparisons in empirical studies. Thus there is a clear need for more rigorous construct development in this area. As to organizational cultural differences, it should be noted that we 
asked the respondents to evaluate organizational cultural differences. This may have resulted in a bias towards the desirable response. Instead of posing questions about cultural differences, scholars could ask the respondents to assess aspects of organizational cultures in more concrete terms. For instance, the organizational cultural type framework developed by Cameron and Quinn (2006) or other similar frameworks (Ashkanasy et al., 2000) could be used to determine the organizational culture type separately for the acquiring and the acquired firm. This method would provide more definitive information about the organizational cultures, allow more objective comparisons of the two organizational cultures, and possibly reduce the response bias by making the intent of the research less obvious to the respondent. In addition, the measure for organizational cultural crossvergence consisted of only three items, and included general terms such as "new culture" and "new identity". Thus this measure is unlikely to reflect the full complexity of the concept. To the best of our knowledge, this is the first acquisition study that has attempted to measure organizational cultural crossvergence quantitatively. Although we consider our conceptualization as a useful starting point, we acknowledge that the operationalization of crossvergence will require more development in future studies (see also Ralston, 2008; Tung, 2008; Witt, 2008). Moreover, the impact mechanisms of operational integration could be more complex than explored in this study. For instance, operational integration could be a facilitator only in some functional areas, or it could emerge as an outcome of knowledge transfer. This suggests that the conceptualization of operational integration and the related analysis should be further developed to understand its full impact on knowledge transfer.

Hence we do not consider this analysis to be the final word on cultural dynamics and knowledge transfer in international acquisitions. We hope instead that it will pave the way for further more detailed analysis of the key issues. In addition to the issues mentioned above, it would be important to examine whether our findings also hold in other historical and cultural circumstances. It would also be interesting to further analyze the micro-processes of cultural integration to better understand how they are linked to knowledge transfer. This can be done by including the individual level of analysis in surveys, and/or analyses based on extensive databases. Also, the use of longitudinal data would further strengthen the results and confirm the direction of the causality. However, only an in-depth and primarily qualitative study could clarify the exact nature of the cultural processes in post-acquisition integration. Future M\&A research should also further investigate organizational cultural differences and cultural integration. This can be done by developing the measures of organizational cultural 
differences and organizational cultural integration by drawing from existing models in organizational culture literature (Ashkanasy et al., 2000; Cameron \& Quinn, 2006). In addition to increased construct validity and reliability, the use of more elaborate measures of organizational culture would allow future research to answer increasingly complex questions: When the acquiring company has an " $\mathrm{X}$ " type of organizational culture and the acquired company has a "Y" type of culture, what are the implications for post-acquisition integration? When the acquiring and acquired cultures are reversed, what happens? Are these effects moderated by context-specific variables, such as industry or size of the firm? In addition, one should go further in explicating the relationships of cultural variables and knowledge transfer. These analyses could also focus attention on the potential mediating effects of integration approach and strategy (Slangen, 2006). A longitudinal research setting would allow the exploration of learning effects in terms of how firms manage their international acquisitions. It would be interesting to examine, for example, whether firms learn to give more attention to managing the process of cultural integration over time.

Finally, our study has managerial implications. In particular, this analysis underscores the importance of national cultural differences as sources of knowledge transfer. This view, which differs from the mantra of "national cultural differences lead to problems and failure", should be seen as comforting news for managers engaging in international M\&As. Furthermore, our analysis emphasizes that reaping the knowledge transfer benefits requires cultural integration in the form of cultural convergence and crossvergence. Cultural integration is obviously not easy, but the conclusion is clear: Successful cultural integration management is needed to deal not only with "soft issues" but also with "hard ones" - such as value creation through knowledge transfer.

\section{AuthorAffiliation}

[1] Department of Business Administration, Bryan School of Business and Economics, University of North Carolina at Greensboro, Greensboro, USA

[2] Department of Management and Organization, Hanken School of Economics, Helsinki, Finland

[3] EM Lyon Business School, Strategy \& Organization, Lyon, France

Correspondence : E Vaara, Department of Management and Organization, Hanken School of Economics, PO Box 479, 00101 Helsinki, Finland. Tel: +358 503059 359; Fax: +358 94313 275; E-mail: eero.vaara@hanken.fi 


\section{Acknowledgements}

This is a fully co-authored paper, and the authors are listed in alphabetical order. We are very grateful to Rosalie Tung and the three anonymous reviewers for their insights, which have greatly improved the paper. We also thank Paulina Junni and all the students involved in data gathering, and Ingmar Björkman, Tomi Laamanen, David Miller, Jennie Sumelius, and Philippe Very for useful comments.

\section{Footnote}

${ }^{1}$ The small number of firms present in all three periods (less than $10 \%$ of the sample) prevented the use of longitudinal analyses through which the possible learning effects could have been explored.

${ }^{2}$ Following Schein (1990), cultural differences were defined as differences in organizationspecific beliefs, values, and practices between the acquiring and the acquired firm.

Knowledge was defined as the accumulated practical skill or expertise that allows one to do something smoothly and efficiently (Zander \& Kogut, 1995), and knowledge transfer as transferring such knowledge between the acquisition partners. We acknowledge that such broad definitions may have injected some extraneous variance in the results. However, in the survey design we had to take into account that our study would involve a wide variety of companies and industries. We felt that very specific definitions would have been restrictive, and unlikely to be applicable across different cases.

${ }^{3}$ The positive relationship between national cultural differences and knowledge transfer was particularly robust across all alternative measures tested. The interaction terms were significant with Hofstede (1991) and Trompenaars and Hampden-Turner (1998) scores, but not significant with Inglehart et al. (2004) scores. These differences in the results can be explained by the differences in the cultural dimensions included in the indices, the differences in the countries to which the scores are available, and the different time periods during which the indices were created.

${ }^{4}$ The use of factor scores based on varimax rotation in the subsequent regression analyses ensured that there was no multicollinearity between the constructs of organizational cultural convergence and organizational cultural crossvergence.

\section{References}

Abrams, L. C., Cross, R., Lesser, E., \& Levin, D. Z. 2003. Nurturing interpersonal trust in knowledge-sharing networks. Academy of Management Executive , 17 (4): 64-77.

Angwin, D., \& Vaara, E. 2005. Introduction to the special issue. "Connectivity" in merging organizations: Beyond traditional cultural perspectives. Organization Studies , 26 (10): 14451453.

Ashkanasy, N. M., Wilderom, C. P.M, \& Peterson, M. F. 2000. The handbook of organizational culture and climate. Thousand Oaks, CA: Sage.

Barkema, H. G., Bell, J. H., \& Pennings, J. M. 1996. Foreign entry, cultural barriers, and learning. Strategic Management Journal , 17 (2): 151-166. 
Barney, J. 1991. Firm resources and sustained competitive advantage. Journal of Management, 17 (1): 99-120.

Berry, J. W. 1983. Acculturation: A comparative analysis of alternative forms. In R.J. Samuda \& S.L. Woods (Eds) Perspectives in immigrant and minority education : 66-77. Lanham, MD: University Press of America.

Bhagat, R. S., Kedia, B. L., Harveston, P. D., \& Triandis, H. C. 2002. Cultural variations in the cross-border transfer of organizational knowledge: An integrative framework. Academy of Management Review , 27 (2): 204-221.

Birkinshaw, J. 1999. Acquiring intellect: Managing the integration of knowledge-intensive acquisitions. Business Horizons , 42 (3): 33-40.

Birkinshaw, J., Bresman, H., \& Håkanson, L. 2000. Managing the post-acquisition integration process: How the human integration and task integration processes interact to foster value creation. Journal of Management Studies , 37 (3): 395-425.

Björkman, I., Barner-Rasmussen, W., \& Li, L. 2004. Managing knowledge transfer in MNCs: The impact of headquarters control mechanisms. Journal of International Business Studies , 35 (5): 443-455.

Björkman, I., Stahl, G., \& Vaara, E. 2007. Cultural differences and capability transfer in cross-border acquisitions: The mediating roles of capability complementarity, absorptive capacity, and social integration. Journal of International Business Studies , 38 (4): 658-672.

Bresman, H., Birkinshaw, J., \& Nobel, R. 1999. Knowledge transfer in international acquisitions. Journal of International Business Studies , 30 (3): 439-462.

Buono, A. F. 1997. Technology transfer through acquisition. Management Decision , 35 (3): 194-204.

Buono, A. F., Bowditch, J. L., \& Lewis, J. W. 1985. When cultures collide: The anatomy of a merger. Human Relations , 38 (5): 477-500.

Cameron, K. S., \& Quinn, R. E. 2006. Diagnosing and changing organizational culture: Based on the competing values framework, (revised ed.) San Francisco, CA: Jossey-Bass.

Capron, L. 1999. The long-term performance of horizontal acquisitions. Strategic Management Journal , 20 (11): 987-1018.

Capron, L., \& Mitchell, W. 1998. Bilateral resource redeployment and capabilities improvements following horizontal acquisitions, 1988-1992. Industrial and Corporate Change , 7 (3): 453-484.

Capron, L., \& Pistre, N. 2002. When do acquirers earn abnormal returns? Strategic Management Journal , 23 (9): 781-794. 
Capron, L., Dussauge, P., \& Mitchell, W. 1998. Resource redeployment following horizontal acquisitions in Europe and North America, 1988-1992. Strategic Management Journal , 19 (7): 631-662.

Cartwright, S., \& Cooper, C. L. 1993. The psychological impact of merger and acquisition on the individual: A study of building society managers. Human Relations , 46 (3): 327-347.

Cartwright, S., \& Cooper, C. L. 1996. Managing mergers, acquisitions, and strategic alliances . Oxford: Butterworth-Heinemann.

Chakrabarti, R., Gupta-Mukherjee, S., \& Jayaraman, N. 2009. Mars-Venus marriages: Culture and cross-border M\&A. Journal of International Business Studies , 40 (2): 216-236.

Chatterjee, S., Lubatkin, M. H., Schweiger, D. M., \& Weber, Y. 1992. Cultural differences and shareholder value in related mergers: Linking equity and human capital. Strategic Management Journal , 13 (5): 319-334.

Child, J., \& Rodrigues, S. 1996. The role of social identity in the international transfer of knowledge through joint ventures. In S.R. Clegg \& G. Palmer (Eds) The politics of management knowledge : 46-68. London: Sage.

Datta, D. K. 1991. Organizational fit and acquisition performance: Effects of post-acquisition integration. Strategic Management Journal , 12 (4): 281-297.

Deal, T., \& Kennedy, A. 1982. Corporate cultures . Reading, MA: Addition Wesley.

Doz, Y. L., Santos, J., \& Williamson, P. 2001. From global to metanational . Boston, MA: Harvard Business School Press.

Elsass, P. M., \& Veiga, J. F. 1994. Acculturation in acquired organizations: A force-field perspective. Human Relations , 47 (4): 431-454.

Empson, L. 2000. Merging professional service firms. Business Strategy Review , 11 (2): 3946.

Empson, L. 2001. Fear of exploitation and fear of contamination: Impediments to knowledge transfer in mergers between professional service firms. Human Relations , 54 (7): 839-862.

Etzioni, A. 1961. A comparative analysis of complex organizations . New York: Free Press.

Foss, N., \& Pedersen, T. 2002. Transferring knowledge in MNCs: The role of sources of subsidiary knowledge and organizational context. Journal of International Management , 8 (1): 49-67.

Fukuyama, F. 1996. Trust: The social virtues and the creation of prosperity . New York: Free Press.

Ghoshal, S. 1987. Global strategy: An organizing framework. Strategic Management Journal , 8 (5): 425-441. 
Grant, R. M. 1996. Toward a knowledge-based theory of the firm. Strategic Management Journal , 17 (Special Issue): 109-122.

Greenwood, R., Hinings, C. R., \& Brown, J. 1994. Merging professional service firms. Organization Science , 5 (2): 239-257.

Gupta, A. K., \& Govindarajan, V. 2000. Knowledge flows within multinational corporations. Strategic Management Journal , 21 (4): 473-496.

Hair, J., Anderson, R. E., Tatham, R. L., \& Black, W. 1998. Multivariate data analysis with readings . Englewood Cliffs, NJ: Prentice Hall.

Haleblian, J., \& Finkelstein, S. 1999. The influence of organizational acquisition experience on acquisition performance: A behavioral learning perspective. Administrative Science Quarterly, 44 (1): 29-56.

Harzing, A. 2003. The role of culture in entry-mode studies: From neglect to myopia? In J.L.C. Cheng \& M.A. Hitt (Eds) Advances in international management , Vol. 15 75-127. Amsterdam: JAI Press.

Haspeslagh, P., \& Jemison, D. B. 1991. Managing acquisitions: Creating value through corporate renewal . New York: The Free Press.

Hébert, L., Very, P., \& Beamish, P. W. 2005. Expatriation as a bridge over troubled water: A knowledge-based perspective applied to cross-border acquisitions. Organization Studies , 26 (10): 1455-1476.

Hitt, M. A., Hoskisson, R. E., \& Ireland, R. D. 1990. Mergers and acquisitions and managerial commitment to innovation in M-form firms. Strategic Management Journal , 11 (10): 29-47.

Hofstede, G. 1980. Culture's consequences: International differences in work-related values . London: Sage Publications.

Hofstede, G. 1991. Cultures and organizations: Software of the mind . London: McGraw-Hill.

Hogg, M. A., \& Terry, D. J. 2000. Social identity and self-categorization processes in organizational contexts. Academy of Management Review , 25 (1): 121-140.

House, R. J., Hanges, P. W., Javidan, M., Dorfman, P., \& Gupta, V. 2004. Culture, leadership, and organizations: The GLOBE study of 62 societies . Beverly Hills, CA: Sage.

Inglehart, R., Basáñez, M., Díez-Medrano, J., Halman, L., \& Luijkz, R. 2004. Human beliefs and values: A cross-cultural sourcebook based on the 1999-2002 values surveys . Mexico: Siglo veintiuno editors.

Kamoche, K. 1997. Knowledge creation and learning in international HRM. International Journal of Human Resource Management , 8 (2): 213-225. 
Kang, S., Morris, S. S., \& Snell, S. A. 2007. Relational archetypes, organizational learning, and value creation: Extending the human resource architecture. Academy of Management Review , 32 (1): 236-256.

Karim, S., \& Mitchell, W. 2000. Path-dependent and path-breaking change: Reconfiguring business resources following acquisitions in the US medical sector, 1978-1995. Strategic Management Journal , 21 (10-11): 1061-1081.

Kedia, B., \& Bhagat, R. 1988. Cultural constraints on transfer of technology across nations: Implications for research in international and comparative management. Academy of Management Review , 13 (4): 559-571.

Khrishnan, H. A., \& Park, D. 2003. Power in acquired top management teams and postacquisition performance: A conceptual framework. International Journal of Management , 20 (1): $75-80$.

King, D. R., Dalton, D. R., Daily, C. M., \& Covin, J. G. 2004. Meta-analyses of postacquisition performance: Indications of unidentified moderators. Strategic Management Journal , 25 (2): 187-200.

Kirkman, B., Lowe, K., \& Gibson, C. 2006. A quarter century of Culture's Consequences : A review of empirical research incorporating Hofstede's cultural values framework. Journal of International Business Studies , 37 (3): 285-320.

Kogut, B., \& Singh, H. 1988. The effect of national culture on the choice of entry mode. Journal of International Business Studies , 19 (3): 411-432.

Kusewitt, J. B. 1985. An exploratory study of strategic acquisition factors relating to performance. Strategic Management Journal , 6 (2): 151-169.

Larsson, R., \& Finkelstein, S. 1999. Integrating strategic, organizational, and human resource perspectives on mergers and acquisitions: A case survey of synergy realization. Organization Science, 10 (1): 1-26.

Larsson, R., \& Lubatkin, M. 2001. Achieving acculturation in mergers and acquisitions: An international case survey. Human Relations , 54 (12): 1573-1607.

Lubatkin, M., Calori, R., Very, P., \& Veiga, J. 1998. Managing mergers across borders: A two-nation exploration of a nationally bound administrative heritage. Organization Science, 9 (6): 670-684.

Lubatkin, M., Schweiger, D., \& Weber, Y. 1999. Top management turnover in related M\&As: An additional test of the theory of relative standing. Journal of Management , 25 (1): 55-73.

McAllister, D. J. 1995. Affect- and cognition-based trust as foundations for interpersonal cooperation in organizations. Academy of Management Journal , 38 (1): 24-59.

McSweeney, B. 2002. Hofstede's model of national cultural differences and their consequences: A triumph of faith - a failure of analysis. Human Relations , 55 (1): 89-118. 
Mirvis, P. H., \& Marks, M. L. 1992a. Managing the merger: Making it work . Englewood Cliffs, NJ: Prentice Hall.

Mirvis, P. H., \& Marks, M. L. 1992b. The human side of merger planning: Assessing and analyzing "fit". Human Resource Planning , 15 (3): 69-92.

Morosini, P., Shane, S., \& Singh, H. 1994. Post-cross-border acquisitions: Implementing 'national culture-compatible' strategies to improve performance. European Management Journal , 12 (4): 390-400.

Morosini, P., Shane, S., \& Singh, H. 1998. National cultural distance and cross-border acquisition performance. Journal of International Business Studies , 29 (1): 137-157.

Nahapiet, J., \& Ghoshal, S. 1998. Social capital, intellectual capital, and the organizational advantage. Academy of Management Review , 23 (2): 242-266.

Nahavandi, A., \& Malekzadeh, A. R. 1988. Acculturation in mergers and acquisitions. Academy of Management Review , 13 (1): 79-90.

Napier, N. K., Simmons, G., \& Stratton, K. 1989. Communication during a merger: The experience of two banks. Human Resource Planning , 12 (2): 105-122.

Newman, V., \& Chaharbagi, K. 1998. The corporate culture myth. Long Range Planning , 31 (4): 514-522.

Nonaka, I. 1994. A dynamic theory of organizational knowledge creation. Organization Science , 5 (1): 14-27.

Olie, R. 1994. Shades of culture and institutions in international mergers. Organization Studies , 15 (3): 381-405.

Ouchi, W. G. 1980. Markets, bureaucracies, and clans. Administrative Science Quarterly, 25 (1): 129-141.

Pablo, A. L. 1994. Determinants of acquisition integration level: A decision-making perspective. Academy of Management Journal , 37 (4): 803-836.

Peters, T. J., \& Waterman, R. H. 1982. In search of excellence: Lessons from America's bestrun companies . New York: Harper \& Row.

Pettigrew, A. M. 1979. On studying organizational cultures. Academy of Management Review , 24 (4): 570-581.

Pfeffer, J., \& Salancik, G. R. 1977. Organizational context and the characteristics and tenure of hospital administrators. Academy of Management Journal , 20 (1): 74-88.

Podsakoff, P. M., McKenzie, S. B., Lee, J., \& Podsakoff, N. P. 2003. Common method biases in behavioral research: A critical review of the literature and recommended remedies. Journal of Applied Psychology , 88 (5): 879-903. 
Porrini, P. 2004. Can a previous alliance between an acquired and a target affect acquisition performance? Journal of Management , 30 (4): 545-562.

Ralston, D. A. 2008. The crossvergence perspective: Reflections and projections. Journal of International Business Studies , 39 (1): 27-40.

Ralston, D. A., Holt, D. H., Terpstra, R. H., \& Kai-Cheng, Y. 1997. The impact of national culture and economic ideology on managerial work values: A study of the United States, Russia, Japan, and China. Journal of International Business Studies , 28 (1): 177-207.

Ranft, A., \& Lord, M. 2000. Acquiring new knowledge: The role of retaining human capital in acquisitions of high-tech firms. Journal of High Technology Management Research, 11 (2): 295-319.

Ranft, A., \& Lord, M. 2002. Acquiring new technologies and capabilities: A grounded model of acquisition implementation. Organization Science , 13 (4): 420-441.

Renzl, B. 2008. Trust in management and knowledge sharing: The mediating effects of fear and knowledge documentation. International Journal of Management Science , 36 (2): 206220.

Riad, S. 2005. The power of "organizational culture" as a discursive formation in merger integration. Organization Studies , 26 (10): 1529-1554.

Sales, A. L., \& Mirvis, P. H. 1984. When cultures collide: Issues of acquisition. In J.R. Kimberly \& R.E. Quinn (Eds) Managing organizational transitions : 107-133. Homewood, IL: Irwin.

Schein, E. 1990. Organizational culture. American Psychologist , 45 (2): 109-119.

Schwartz, S. H. 2004. Mapping and interpreting cultural differences around the world. In H. Vinken, J. Soeters \& P. Ester (Eds) Comparing cultures: Dimensions of culture in a comparative perspective : 43-73. Leiden: Brill.

Schweiger, D. M., \& DeNisi, A. S. 1991. Communication with employees following a merger: A longitudinal field experiment. Academy of Management Journal , 34 (1): 110-135.

Schweiger, D. M., \& Goulet, P. K. 2005. Facilitating acquisition integration through deeplevel cultural learning interventions: A longitudinal field experiment. Organization Studies , 26 (10): 1477-1499.

Selznick, P. 1965. RVA and the grass roots . New York: Harper Torchbooks.

Shenkar, O. 2001. Cultural distance revisited: Towards a more rigorous conceptualization and measurement of cultural differences. Journal of International Business Studies , 32 (3): 519535.

Shrivastava, P. 1986. Postmerger integration. Journal of Business Strategy , 7 (1): 65-76. 
Slangen, A. H. 2006. National cultural distance and initial foreign acquisition performance: The moderating effect of integration. Journal of World Business , 41 (2): 161-170.

Stahl, G. K., \& Voigt, A. 2005. Impact of cultural differences on merger and acquisition performance: A critical research review and an integrative model. In C.L. Cooper \& S. Finkelstein (Eds) Advances in mergers and acquisitions , Vol. 4. 51-83. Amsterdam: JAI Press.

Stahl, G. K., \& Voigt, A. 2008. Do cultural differences matter in mergers and acquisitions? A tentative model and examination. Organization Science , 19 (1): 160-176.

Szulanski, G. 1996. Exploring internal stickiness: Impediments to the transfer of best practice within the firm. Strategic Management Journal , 17 (1): 27-43.

Tayeb, M. 1994. Organizations and national culture: Methodology considered. Organization Studies , 15 (3): 429.

Teece, D. J., Pisano, G., \& Shuen, A. 1997. Dynamic capabilities and strategic management. Strategic Management Journal , 18 (7): 509-533.

Teerikangas, S., \& Very, P. 2006. The culture-performance relationship in M\&A: From yes/no to how. British Journal of Management , 17 : S31-S48.

Trompenaars, F., \& Hampden-Turner, C. 1998. Riding the waves of culture: Understanding cultural diversity in business . London: Nicholas Brealey Publishing.

Tung, R. 2008. The cross-cultural research imperative: The need to balance cross-national and intra-national diversity. Journal of International Business Studies , 39 (1): 41-46.

Vaara, E. 2003. Post-acquisition integration as sensemaking: Glimpses of ambiguity, confusion, hypocrisy, and politicization. Journal of Management Studies , 40 (4): 859-894.

Vaara, E., Tienari, J., \& Björkman, I. 2003a. Best practice is West practice? A sensemaking perspective on knowledge transfer. In: A.-M. Søderberg \& E. Vaara (Eds) Merging across borders : 111-138. Denmark: Copenhagen Business School Press.

Vaara, E., Tienari, J., \& Säntti, R. 2003b. The international match: Metaphors as vehicles of social identity building in cross-border mergers. Human Relations , 56 (4): 419-451.

Vaara, E., Tienari, J., \& Irrmann, O. 2007. Crafting an inter-national identity: The Nordea case. In L. Lerpold, D. Ravasi, J. van Rekom \& G. Soenen (Eds) Organizational identity in practice : 215-231. London: Routledge.

Van Knippenberg, D., \& Van Leeuwen, E. 2001. Organizational identity after a merger: Sense of continuity as the key to post-merger identification. In M.A. Hogg \& D.J. Terry (Eds) Social identity processes in organizational contexts : 249-264. Philadelphia, PA: Psychology Press. 
Veiga, J., Lubatkin, M., Calori, R., \& Very, P. 2000. Measuring organizational culture clashes: A two-nation post-hoc analysis of a cultural compatibility index. Human Relations , 53 (4): 539-557.

Very, P., Calori, R., \& Lubatkin, M. 1993. An investigation of national and organizational cultural influences on recent European mergers. In P. Shrivastava, A. Huff \& J. Dutton (Eds) Advances in strategic management, Vol. 9. 323-346. London: JAI Press.

Very, P., Lubatkin, M., Calori, R., \& Veiga, J. 1997. Relative standing and the performance of recently acquired European firms. Strategic Management Journal , 18 (8): 593-614.

Weber, Y. 1996. Corporate cultural fit and performance in mergers and acquisitions. Information \& Management , 30 (2): 81-90.

Weber, Y., Shenkar, O., \& Raveh, A. 1996. National and corporate cultural fit in mergers/acquisitions: An exploratory study. Management Science , 42 (8): 1215-1227.

Williams, M. 2001. In whom we trust: Group membership as an affective context for trust development. Academy of Management Review , 26 (3): 377-396.

Witt, M. E. 2008. Crossvergence 10 years on: Impact and further potential. Journal of International Business Studies , 39 (1): 47-52.

Zaheer, A., McEvily, B., \& Perrone, V. 1998. Does trust matter? Exploring the effects of interorganizational and interpersonal trust on performance. Organizational Science , 9 (2): 141-159.

Zander, U. 1991. Exploiting a technological edge: Voluntary and involuntary dissemination of technology. Stockholm: Institute of International Business.

Zander, U., \& Kogut, B. 1995. Knowledge and the speed of the transfer and imitation of organizational capabilities: An empirical test. Organization Science , 6 (1): 76-92. 


\section{Appendix}

\section{APPENDIX A}

Table A1 Background information on the respondents

Respondent’s background

Percentage of total responses

$(\mathrm{N}=236)$

Gender

Male

Female

Firm side

Acquiring firm

Acquired firm

Position

Respondent is the CEO

Respondent belongs to the top management but is not the CEO

Respondent is a board member

Respondent's experience of previous acquisitions (a)

Involved in 0 acquisitions

Involved in $1-5$ acquisitions

Involved in 6-10 acquisitions

22.0

Involved in over 10 acquisitions

Respondent's involvement in pre-acquisition decision-making (b)

Low involvement

Medium involvement

High involvement

Respondent's involvement in post-acquisition integration decision-making

Low involvement

Medium involvement

High involvement

(a) The respondents were asked to give the total number of acquisitions that they had previously been involved in. In this table, the responses have been aggregated to four categories.

(b) The respondents were asked to evaluate their involvement in the preacquisition decision-making process on a Likert scale from 1/1/4little involvement to $71 / 4$ considerable involvement. In this table, the responses have been aggregated to three categories: low involvement includes the Likert-scale answers 1 and 2, medium involvement corresponds to the Likert-scale answers 3 and 4, and high involvement contains the Likert-scale answers 5, 6, and 7. A similar aggregation approach was used when reporting the respondents' involvement in the post-acquisition integration decision-making. 


\section{APPENDIX B}

\section{The Survey Questions}

The survey asked respondents to circle the best response to each question.

Knowledge transfer (a)

\begin{tabular}{lcccccccc}
\hline $\begin{array}{l}\text { In your opinion, has knowledge transfer resulted in benefits in the } \\
\text { following operations? }\end{array}$ & Not at all & & & & & $\begin{array}{c}\text { Very } \\
\text { much }\end{array}$ \\
\hline Management and control & 1 & 2 & 3 & 4 & 5 & 6 & 7 \\
Sales and marketing & 1 & 2 & 3 & 4 & 5 & 6 & 7 \\
Production & 1 & 2 & 3 & 4 & 5 & 6 & 7 \\
Research and development & 1 & 2 & 3 & 4 & 5 & 6 & 7 \\
Finance & 1 & 2 & 3 & 4 & 5 & 6 & 7 \\
\hline
\end{tabular}

(a) We do not report Cronbach alpha's for knowledge transfer and organizational cultural differences, because it can be argued that different organizational functions are not conceptually related. Cronbach's alpha would therefore be an inappropriate measure. Adapted measures from Bresman et al. (1999), Ranft \& Lord (2000), and Capron et al. (1998).

\section{Organizational Cultural Differences Before the Acquisition}

In your opinion, has knowledge transfer resulted in benefits in the following operations?

\begin{tabular}{cccccccc} 
No & & & & & & $\begin{array}{c}\text { Significant } \\
\text { differences }\end{array}$ \\
differences & & & & & & \\
1 & 2 & 3 & 4 & 5 & 6 & 7 \\
1 & 2 & 3 & 4 & 5 & 6 & 7 \\
1 & 2 & 3 & 4 & 5 & 6 & 7 \\
1 & 2 & 3 & 4 & 5 & 6 & 7 \\
& 2 & 3 & 4 & 5 & 6 & 7 \\
1 & 2 & 3 & 4 & 5 & 6 & 7 \\
& 1 & 2 & 3 & 4 & 5 & 6 & 7 \\
\hline
\end{tabular}

Management and contro

Sales and marketing

Production

Research and development

Finance

Company values in general

In your opinion, how much did the values of the decision-makers of the

acquiring and the acquired company differ before the acquisition?

Adapted measures from Chatterjee et al. (1992), Lubatkin et al. (1999), Weber (1996), and Weber et al. (1996).

\section{Organizational Cultural Differences After the Acquisition (b)}

\begin{tabular}{|c|c|c|c|c|c|c|c|}
\hline $\begin{array}{l}\text { How would you describe the cultural differences between the companies } \\
\text { at this moment? }\end{array}$ & $\begin{array}{c}\text { No } \\
\text { differences }\end{array}$ & & & & & & $\begin{array}{l}\text { Significant } \\
\text { differences }\end{array}$ \\
\hline Management and control & 1 & 2 & 3 & 4 & 5 & 6 & 7 \\
\hline Sales and marketing & 1 & 2 & 3 & 4 & 5 & 6 & 7 \\
\hline Production & 1 & 2 & 3 & 4 & 5 & 6 & 7 \\
\hline Research and development & 1 & 2 & 3 & 4 & 5 & 6 & 7 \\
\hline Finance & 1 & 2 & 3 & 4 & 5 & 6 & 7 \\
\hline Company values in general & 1 & 2 & 3 & 4 & 5 & 6 & 7 \\
\hline $\begin{array}{l}\text { In your opinion, how much do the values of the decision-makers of the } \\
\text { acquiring and the acquired company differ at this moment? }\end{array}$ & 1 & 2 & 3 & 4 & 5 & 6 & 7 \\
\hline
\end{tabular}

(b) The measure "'organizational cultural convergence”' was built by subtracting the mean of organizational cultural differences after the acquisition from the mean of organizational cultural differences before the acquisition. Birkinshaw et al. (2000) measured cultural convergence in the acquisition context using a similar approach based on changes in organizational cultural differences. However, their measure was designed to suit the R\&D context, and therefore was adapted to our study. 
Very

To what extent has new culture shared by both companies been created To what extent has new identity shared by both companies been created after the acquisition?

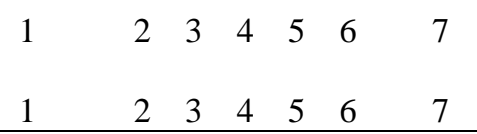

\begin{tabular}{llllllllllll}
\hline & \multicolumn{1}{l}{ Not } & & \multicolumn{3}{c}{$\begin{array}{c}\text { Very } \\
\text { much }\end{array}$} \\
\hline $\begin{array}{l}\text { The practices have been standardized } \\
\text { by changing the old practices to better } \\
\text { fit each other }\end{array}$ & 1 & 2 & 3 & 4 & 5 & 6 & 7 & $\begin{array}{l}\text { The practices have been standardized } \\
\text { by creating new practices }\end{array}$ \\
\hline
\end{tabular}

Derived from previous theoretical and qualitative literature (e.g., Elsass \& Veiga, 1994; Mirvis \& Marks, 1992a, 1992b; Nahavandi \& Malekzadeh, 1988; Van Knippenberg \& Van Leeuwen, 2001) as well as from in-depth background interviews and subsequent generation, pre-testing, and refinement of items. Cronbach's alpha=0.60.

\section{Control Variables}

\section{Operational integration effort}

How would you describe the number of changes made in the acquiring company?
No changes
12
3
45
6
$7 \quad$ Significant changes

How would you describe the number of changes made in the acquired company?

\begin{tabular}{lllllllll} 
No changes & 1 & 2 & 3 & 4 & 5 & 6 & 7 & Significant changes \\
\hline
\end{tabular}

\begin{tabular}{|c|c|c|c|c|c|c|c|}
\hline & $\begin{array}{c}\text { Not at } \\
\text { all }\end{array}$ & & & & & & $\begin{array}{c}\text { A great } \\
\text { deal }\end{array}$ \\
\hline To which extent have the overlappings (c) been eliminated? & 1 & 2 & 3 & 4 & 5 & 6 & 7 \\
\hline $\begin{array}{l}\text { To which extent has there been a tendency towards the standardization of } \\
\text { practices? }\end{array}$ & 1 & 2 & 3 & 4 & 5 & 6 & 7 \\
\hline
\end{tabular}

(c) “'Overlappings" were defined as "operations of the acquiring and the acquired firms that have considerable similarities to the extent that they overlap"'. In the questionnaire, this definition was provided in a preceding question that was not included in this analysis. Therefore we did not repeat the definition of "overlappings" in the wording of this specific question.

Derived from previous research and measures related to the extent of operational integration effort (Khrishnan \& Park, 2003; Larsson \& Lubatkin, 2001; Lubatkin et al., 1998; Morosini et al., 1994; Weber et al., 1996). Cronbach’s alpha=0.65.

\section{Autonomy}

To what extent have the values of the acquiring company dominated in the integration process?
Very much
12
3
45
$6 \quad 7$ Not at all

Under how tight control has the acquired company been operating after the acquisition?

Extremely tight control

1

23

4

Fully

Fully
independently


The changes have been based on the acquiring company's practices

The management of the acquirer has dominated the integration

The changes have been based decisions on the acquired company's practices

Adapted measures of organizational autonomy used in previous acquisition research (Larsson \& Finkelstein, 1999; Morosini

\section{ABOUT THE AUTHORS}

Riikka M. Sarala is an Assistant Professor of International Business at the University of North Carolina at Greensboro. She earned her PhD at Hanken School of Economics. Her research interests include international mergers and acquisitions, national and organizational culture, global strategies, and knowledge transfer. She was born in Finland, remains a Finnish citizen, and resides in the US. E-mail:

rmsarala@uncg.edu

Eero Vaara is Professor of Management and Organization at Hanken School of Economics in Helsinki, Finland, and permanent Visiting Professor at EM Lyon Business School, France. He is also the Chair of EGOS (European Group for Organizational Studies). He got his PhD at Helsinki School of Economics. His research interests focus on organizational change (especially M\&As), multinational enterprises and globalization, strategy and strategizing, the role of the media in organizing and management, and methodological issues in organization and management research. E-mail:

eero.vaara@hanken.fi 